\title{
Low protein diet: its relevance to Manganese-induced neurotoxicity in rats treated with Coenzyme Q10 and/or Epigallocatechin-3-gallate.
}

\author{
Amany S. Aboutaleb ${ }^{a^{*}}$, Hebatalla I. Ahmed ${ }^{a}$, Mona M. Kamala , Azza A. Alia \\ a Department of Pharmacology and Toxicology, Faculty of Pharmacy, Al-Azhar University, Cairo, Egypt. \\ ** Corresponding Author: amany s aboutaleb@yahoo.com: amanyabdelrhman2579.el@azhar.edu.eg,
}

Department of Pharmacology Faculty of Pharmacy, Al-Azhar University, Cairo, Egypt, Tel.: +966563685881

Article history: Received: 16-2-2021

Revised:1-6-2021

Accepted: 21-6-2021

\begin{abstract}
Manganism is a neurotoxic condition causing a parkinsonian-like symptom and results from excessive exposure to Manganese (Mn). Coenzyme Q10 and Epigallocatechin-3-gallate (EGCG) are promising neuroprotective agents. A low protein diet, a noteworthy problem in developing countries, leads to various health problems. So, this study was designed to assess the role of a low protein diet during induction and treatment of Manganism using Co-enzyme Q10, EGCG, or their combinations. Two sets of rats, normally fed (NF) (20\% casein) and low protein diet-fed (10\% casein) rats, were subdivided into five groups; control and four $\mathrm{MnCl}_{2}(10 \mathrm{mg} / \mathrm{kg})$ groups, three of them were treated with either Co-enzyme Q10 (200mg/kg), EGCG $(25 \mathrm{mg} / \mathrm{kg})$, or their combination. Four behavioral tests: grid, swimming, open-field, and Y-maze were done. Biochemical changes in monoamines, oxidative stress biomarkers, neuroinflammatory markers, BDNF, and Complex-I were also measured in the striatum. Moreover, serum albumin content and brain histopathological changes were examined. Revealing that $\mathrm{MnCl}_{2}$ induced an increase in catalepsy and a decrease in locomotor, emotionality, and exploratory activities with impairment of spatial memory, as well as delay in decision making and disruption in neuromuscular coordination and vigilance with changes in biochemical and histopathological examinations. All tested treatments enhanced most behavioral, biochemical, and histopathological impairments in the striatum, with a more pronounced effect of the combination. Low protein diet-fed rats showed slight improvement against Mn-induced neurotoxicity. In conclusion: Low protein diet showed pronounced improvement compared to the corresponding normally fed rats against Mn-induced neuronal degeneration either alone or treated.
\end{abstract}

Keywords: Parkinsonism; Manganese; low protein diet; Co-enzyme Q10; Epigallocatechin-3-gallate; rats.

\section{INTRODUCTION}

Parkinson's disease (PD) is one of the most common neurodegenerative diseases (NDD) in the elderly over 60 years all over the world. It has motor and non-motor symptoms; Tremors, stiffness, and slow movement as well as depression and emotional changes ${ }^{1}$. Scientists explained the neuronal degeneration in PD by different theories: apoptosis, immunological mechanism, proteolysis defects, oxidative stress, mitochondrial dysfunction, iron metabolism disorders, and protein misfolding; causing neuronal dysfunction, atrophy, and cell death $^{2}$. Genes mutation like alpha-synuclein $(\alpha-$ syn), Parkin, PINK, LRRK2, and other genes may be considered as the genetic etiology of PD representing $10 \%$ of cases $^{3,4}$. PD has neuropathological changes including the formation of abnormal proteinaceous bodies called Lewy bodies (LBs) and Lewy neurites
(LNs) in the affected nerve cells ${ }^{5}$. The risk factors of PD are age, environmental and genetic factors ${ }^{6}$. Environmental factors play a crucial role in the progression of PD in the form of pesticide exposure ${ }^{7}$. Excessive manganese exposure in industry and agriculture increased the risk of $\mathrm{PD}^{8}$ and results in a neurotoxic condition called Manganism which causes symptoms like PD symptoms.

Manganese (Mn) is an abundant micronutrient for normal body development 9 . It is not absorbed through the gastrointestinal tract, but also through the lungs after inhalation ${ }^{10}$. It mainly accumulates in the liver, brain, and bone ${ }^{11,12}$ and passes the blood-brain barrier (BBB) and crosses calcium (Ca2+) channels, which present in mitochondria and accumulate in it inducing oxidative stress; Mn uptake may occur through the dopamine transporter (DAT). Mn also binds to residues of $\alpha$-Syn, causing $\alpha$-Syn

Cite this article: Aboutaleb, A., Ahmed, H., Kamal, M., Ali, A. Low protein diet: its relevance to Manganese-induced neurotoxicity in32 rats treated with Coenzyme Q10 and/or Epigallocatechin-3-gallate.. Azhar International Journal of Pharmaceutical and Medical Sciences, 2021; 1(3): 32 -55. doi: 10.21608/aijpms.2021.62632.1048 
oligomerization by oxidative stress. All these events contribute to its risk of PD and Manganism ${ }^{13}$.

A low protein diet in adulthood leads to hypothalamus malfunctions and behavioral abnormalities $^{14}$; There are published data reporting that increasing protein in the diet increased the risk of PD, but there are no available studies that examined the effect of the concentration of macronutrient in the diet on progression and treatment ${ }^{15}$.

Coenzyme Q10 (CoQ10) is synthesized by the mevalonate pathway in the body ${ }^{16}$ and found in the diet, with higher amounts in heart, chicken leg, herring, and trout. CoQ10 has antioxidant activity and restoring the antioxidant defense system ${ }^{17}$, which has a role in cognitive aging and neurodegenerative disease $^{18}$. CoQ10 also has neuroprotection of the nigrostriatal dopaminergic neurons, up-regulates mitochondrial function, and prevents ATP depletion $^{18}$.

Epigallocatechin-3-gallate (EGCG), of green tea, has important anti-atherogenic, antiinflammatory, and neuroprotective effects ${ }^{19}$. Its neuroprotective effects are caused by antioxidant, anti-inflammatory, and iron-chelating properties ${ }^{20}$. EGCG can pass BBB and in neurons catechin stimulates cell survival and inhibits cell death ${ }^{21-23}$ : promoting cognition and increasing cerebral activity and calmness ${ }^{24}$.

\section{METHODS}

\subsection{Animals:}

In this study One hundred adult Sprague Dawley male rats, (300-340 g), purchased from the Nile Co. for Pharmaceuticals and Chemical Industries, Cairo, Egypt. They were kept under adequate environmental conditions and provided with their daily food requirements of standard diet pellets (El-Nasr, Abu Zaabal, Cairo, Egypt) and water ad-libitum according to the Guide for the Care and Use of Laboratory Animals published by the U.S. National Institutes of Health and is approved by the Ethics Committee of Faculty of Pharmacy (Girls), Al-Azhar University, Egypt, Permit Number 203, 2016. Three weeks before starting the experiment, they were shifted to a special diet and daily provided with a standard protein diet $[20 \%$ casein diet]; contained protein (20\%), fiber (5\%), fat (3.5\%), ash (6.5\%) as well as vitamin mixture (ElNasr, Abu Zaabal, Cairo, Egypt), for normally-fed (NF) rats and low protein diet [10\% casein diet] for low protein diet-fed rats $^{25}$.

\subsection{Drugs:}

Manganese (II) chloride tetrahydrate $\left(\mathrm{MnCl}_{2} .4 \mathrm{H}_{2} \mathrm{O}\right)$ and Epigallocatechin-3-gallate (EGCG) were purchased from Sigma-Aldrich
Chemical Co., St. Louis, MO, USA. $\mathrm{MnCl}_{2} .4 \mathrm{H}_{2} \mathrm{O}$ and EGCG were freshly dissolved in saline (sodium chloride "NaCl", 0.9\%, "El-Nasr"). Co-enzyme Q10 (Co Q10) was purchased as Co Q10 (30 mg) Hard Gelatin Capsules obtained from Mepaco-Arab Company for pharmaceuticals and Medical plants, Cairo, Egypt, the content of the capsule was suspended in $1 \%$ aqueous solution of Tween 80 ; the suspension was freshly prepared.

\subsection{Experimental design:}

Animals were erratically dispersed into ten groups (10 rats/group); five of them (NF) were served with $20 \%$ casein diet and the other five (low protein diet - fed) with $10 \%$ casein diet ${ }^{25}$ for eight weeks. After three weeks of experimental special diet start, NF and low protein diet-fed rats' groups were treated as follows; one was the control group and injected with saline (I.P.) and given saline suspended with tween 80 orally daily, the other four groups were injected daily with $\mathrm{MnCl}_{2} .4 \mathrm{H}_{2} \mathrm{O}(10 \mathrm{mg} / \mathrm{kg}$ I.P daily $)^{26}$. One of these four groups served as $\mathrm{Mn}$ toxicity model groups, while the remaining three groups were treated with Co Q10 $(200 \mathrm{mg} / \mathrm{kg}$, P.O daily $)^{25}$, EGCG $(25 \mathrm{mg} / \mathrm{kg} \text {, I.P daily })^{27}$ and a combination of both with $\mathrm{MnCl}_{2}$ during the remaining five consecutive weeks concurrently with Mn-toxicity induction. The dose volume for all tested drugs was not exceeded $0.5 \mathrm{ml} / 200 \mathrm{~g}$ body weight. After the first three weeks, blood samples were collected from the retro-orbital venous plexus of control NF and low protein diet-fed groups to confirm the nutritional status by determination of serum albumin content. Serum samples were gained by centrifugation at $3000 \mathrm{rpm}$ for $10 \mathrm{~min}$. At the end of the eight weeks, behavioral tests were performed for all the aforementioned groups of animals the day after the last injection of drugs sequentially by the following order: grid test, swimming test, open-field test, and $\mathrm{Y}$ maze test. One day after the last behavioral test, rats were anesthetized with chloralhydrate and full brains were dissected and washed with ice-cold saline. The striatum of eight brains from each group was isolated, bathed with icecold saline, and stored immediately at $-80{ }^{\circ} \mathrm{C}$ for biochemical analysis. The remaining two brains from each group were kept in $10 \%$ formaldehyde for histopathological examinations; specimens from different areas of the brain were examined for all treated groups. The homogenates of the striatum tissues in saline were used to evaluate the monoamine content (DA, 5-HT, and NE), oxidative stress markers (SOD, TAC, and MDA), antiinflammatory markers (TNF- $\alpha$ and COX-II), Brainderived neurotrophic factor (BDNF) and Mitochondrial respiratory chain Complex-I content. 


\subsection{Measured parameters:}

2.4.1. Assessment of the effect of a low protein diet:

Serum albumin content was tested using Stanbio Laboratory Inc ready-made kits. (San Antonio, USA) following the manufacturer's instruction.

2.4.2. Catalepsy test (grid test): is of great significance because it detects the main symptoms of Parkinson's disease: akinesia, bradykinesia, and rigidity $^{28}$. It is a vertical grid $(25.5 \times 44 \mathrm{~cm}$ with $1 \mathrm{~cm}$ space wire), on which the rat was hung by its four paws and the time is taken by the rat to move any of its paws was detected and called the movement latency.

2.4.3. Swimming test: measures the time of latency which is the time taken until the animal start to swim, the swimming time which is the time taken by the animal to reach the ramp, and the direction score. These parameters were recorded as an indication for decision making, muscular strength, neuromuscular coordination, awareness and vigilance, attention, and learning ability ${ }^{29}$.

2.4.4. Open-field test: is mostly used to evaluate the locomotor activity and exploratory behavior30,31. The test is done using a wooden squared box $80 \times 80 \times 40 \mathrm{~cm}$ height 32 , with white polished floor, divided into 16 equal squares $4 \times 4$, and red walls 33 . The latency to start the movement is used to evaluate akinesia, while the decrease of locomotion (ambulation) and/or rearing frequency used for hypokinesia31,34. The grooming behavior may involve a dopaminergic mechanism35.

2.4.5. Y-maze test: measures the percentage of spontaneous alternation behavior which estimates short-term memory ${ }^{36}$. The Y-maze is a wooden, black maze with three equal-sized arms labeled A, B, and $\mathrm{C}$, each arm $(12 \times 40 \times 35 \mathrm{~cm}$ height $)$ was positioned at an angle of $120^{\circ}$ from the other two arms $^{37}$. Rats were situated at the end of an arm and allowed to move freely through the maze in an 8- $\mathrm{min}$ session. Spontaneous alternation behavior is the entry into the three arms on sequential alternatives and then the percentage of it was calculated ${ }^{37}$.

\subsubsection{Biochemical analysis:}

Preparation of samples:

Striatum from each brain was minced and homogenized in Phosphate buffered solutions (PBS) with an iced glass homogenizer. Then the minced tissue was lysed by ultrasonication or freeze ($80^{\circ} \mathrm{C}$ )/thaw (room temperature) $2-3$ times. The homogenate was centrifuged at $1500 \times \mathrm{g}$ for 15 minutes. Collect the supernatant for assaying.

\subsubsection{Assesment of striatal monoamine content:}

Monoamines' tissue level (DA, 5-HT, and NA) was estimated in the striatal homogenates of all groups using commercial ready-made kits (Cusabio technology LLC, Houston, USA; LsBio Inc, Seatel, WS, USA and EAGLE Bioscience, Columbia respectively) by quantitative sandwich enzyme immunoassay technique (Elisa) following the manufacturer's instructions.

\subsubsection{Assessment of striatal oxidative stress biomarkers:}

Levels of SOD, TAC, and MDA were assessed in all groups' striatal homogenates using ready-made kits (Cusabio technology LLC, Houston, USA, ZenBio Inc, USA, LsBio Inc, Seatel, WS, USA) by Elisa techniques following the manufacturer's instructions

2.4.6.3. Assessment of striatal inflammatory markers:

Both striatal TNF- $\alpha$ and COX-II levels were quantified by the ELISA technique using commercial ELISA Kits (Ray Biotech Life, USA, IBL International GmBH, Hamburg, Germany) in line with the manufacturer's instructions.

\subsubsection{Assessment of Brain-derived neurotrophic factor (BDNF) content in the striatum:}

BDNF content in the striatum was evaluated in all treated groups using commercial Rat BDNF ELISA Kit (Kamaya biomedical company, USA) in line with the manufacturer's instructions.

\subsubsection{Assessment of Mitochondrial respiratory chain complex-I content in the striatum:}

Striatal content was measured using a commercial mitochondrial Complex-I quantitative sandwich ELISA Kit (Cusabio, Hubei, P.R. China) in line with the manufacturer's instruction.

\subsubsection{Histopathological examination using Hematoxylin and Eosin:}

Isolated brain tissue was set in $10 \%$ formalin solution for $24 \mathrm{~h}$, washed under tap water and then brain sections from the brain were made and stained according to Bancroft and Gamble method ${ }^{38}$ for light microscopy. Serial dilutions of different alcohols (methyl, ethyl, and absolute ethyl) were used for dehydration. Rescue of brain sections was done in xylene embedded in paraffin at $56{ }^{\circ} \mathrm{C}$ in a hot air oven for $24 \mathrm{~h}$. Blocks of paraffin beeswax tissue were used for slicing at $4-\mu \mathrm{m}$ thickness by microtome. Obtained sliced tissue was gathered on glass slides, deparaffinized, and stained with H\&E for histopathological examination. Sections were examined by a qualified blinded pathologist to the experimental tissue.

\subsection{Statistical analysis:}

Results were exemplified as mean \pm standard error of the mean (SEM). Statistical analysis was 
performed using the unpaired t-test for serum albumin content and Two-way analysis of variance (ANOVA) followed by Tukey's multiple comparison test for the other parameters. A level of probability of 0.05 was used as the standard for significance. All statistical analyses and figures were done using GraphPad Prism (ISI, USA) software (version 6).

\section{RESULTS}

\subsection{Serum albumin content of NF and low protein diet-fed rats:}

Keeping rats on a low protein diet (10\% casein) for 3 weeks resulted in a decrease in serum albumin by $99.215 \%$ compared to the corresponding control NF group (Figure 1).

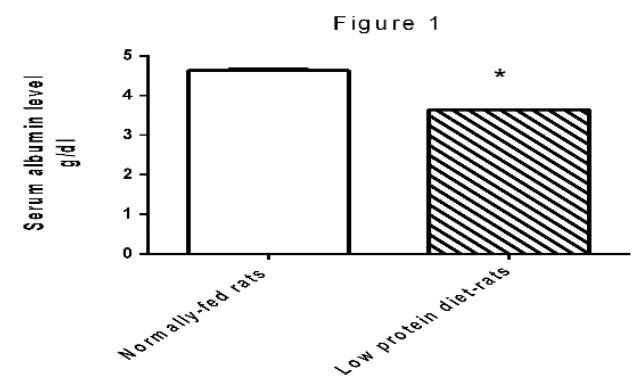

Figure 1: Effect of low protein diet on serum albumin level in rats.Data are expressed as mean + S.E.M. of 25 rats. Analysis of data was carried out using the unpaired t-test. *: significantly different from the corresponding group under normal diet regimen at $\mathrm{p}<0.05$.

\subsection{Behavioral Tests:}

3.3.1. catalepsy duration in grid test:

In $\mathrm{NF}$ rats $\mathrm{MnCl}_{2}$ resulted in akinesia and rigidity displayed as extended catalepsy duration (movement latency) in the grid test by $746.45 \%$ as compared with the control group. Co Q10, EGCG, and combination of both reduced the catalepsy duration by $76.35 \%, 69.83 \%$, and $19.42 \%$ respectively in the grid test as compared with $\mathrm{MnCl}_{2}$ intoxicated rats. Intra-comparing the different treatments, showed a non-significant difference.

While in low protein diet-fed rats, $\mathrm{MnCl}_{2}$ lengthened catalepsy duration (movement latency) in the grid test by $224.03 \%$ as compared with the control group. Co Q10, EGCG, and combination of both reduced the catalepsy duration by $68.98 \%$, $58.69 \%$, and $62.96 \%$ respectively in the grid test as compared with $\mathrm{MnCl}_{2}$ intoxicated rats. Intracomparing the different treatments, showed a nonsignificant difference.

Inter-comparing of the two diet regimens, $\mathrm{MnCl}_{2}$ treated low protein diet-fed rats showed a marked decrease in catalepsy by $99.37 \%$ as compared to the corresponding normally fed group.
Different treatments on a low protein diet did not show any significant change in movement latency as compared to the corresponding NF groups (Figure 2).

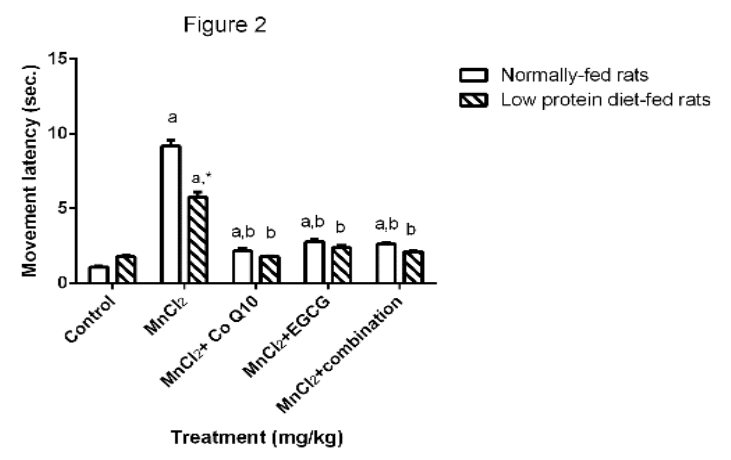

Figure 2: Effect of Co-enzyme Q10 and/or Epigallocatechin gallate on catalepsy duration of Manganese-induced parkinsonism in both normally fed and low protein diet-fed rats in grid test. Control animals received saline I.P. for 35 days. $\mathrm{MnCl} 2$ (10 mg/kg, I.P.), Co-enzyme Q10 (200mg/kg, P.O.), and EGCG (25mg/kg, I.P.) were daily administered for 35 days. Data are expressed as mean + S.E.M. of 10 rats. Analysis of data was carried out using two-way ANOVA followed by Tukey's multiple comparisons test. a: significantly different from the respective control group at $p<0.05$. b: significantly different from the respective $\mathrm{MnCl} 2$ treated group at $\mathrm{p}<0.05$. *: significantly different from the corresponding same group under normal diet regimen at $\mathrm{p}<0.05$.

\subsubsection{Swimming test:}

In $\mathrm{NF}$ rats, $\mathrm{MnCl}_{2}$ showed a delay in decision making, disruption in neuromuscular coordination, and vigilance manifested as swimming latency and time prolongation and reduction in direction score by $338.92 \%, 682.22 \%$, and $75.73 \%$ respectively, as compared to the control rats. Co Q10, EGCG, and combination of both markedly decreased the swimming latency by $61.12 \%, 45.75 \%$, and $61.12 \%$ and swimming time by $74.77 \%, 79.50 \%$, and 82.22 $\%$ and increased direction score by and $106.18 \%$, $112.36 \%$; and $180.90 \%$ respectively as compared to $\mathrm{MnCl}_{2}$ alone treated rats. Intra-comparing of the different treatments showed that EGCG increased the latency by $39.52 \%$ as compared to Co Q10 treated rats and their combination decreased it by $28.33 \%$ as compared to EGCG with a non-significant alteration as compared to Co Q10. As well as a non-significant alteration in the other parameters.

In low protein-diet -fed rats, $\mathrm{MnCl}_{2}$ significantly lengthened the swimming latency and time and reduced direction score by $95.58 \%$, $147.75 \%$, and $43.29 \%$ respectively as compared to control rats. Co Q10, EGCG, and their combination showed an obvious reduction in the latency by 69.01 
$\%, 65.13 \%$, and $65.61 \%$ and swimming time by and $53.79 \%, 62.07 \%$; and $61.30 \%$ respectively, as compared to $\mathrm{MnCl}_{2}$ alone treated rats, along with no significant difference regarding the direction score. Intra-comparing the different treatments, low protein diet-fed rats indicated a non-significant alteration in all parameters.

Inter-comparing of the two diet regimens, $\mathrm{MnCl}_{2}$ treated rats on a low protein diet showed a marked decrease in swimming latency and time and increase in direction score by $40.25 \%, 55.66 \%$, and $112.36 \%$ respectively as compared to the corresponding NF group. Co Q10, EGCG, and their combination in low protein diet-fed rats showed a significant decrease in latency by $52.42 \%, 61.60 \%$, and $47.15 \%$ respectively as compared to the corresponding NF groups. Without any significant alteration regarding the other parameters (Figure 3 $\mathrm{a}, \mathrm{b}, \mathrm{c})$.

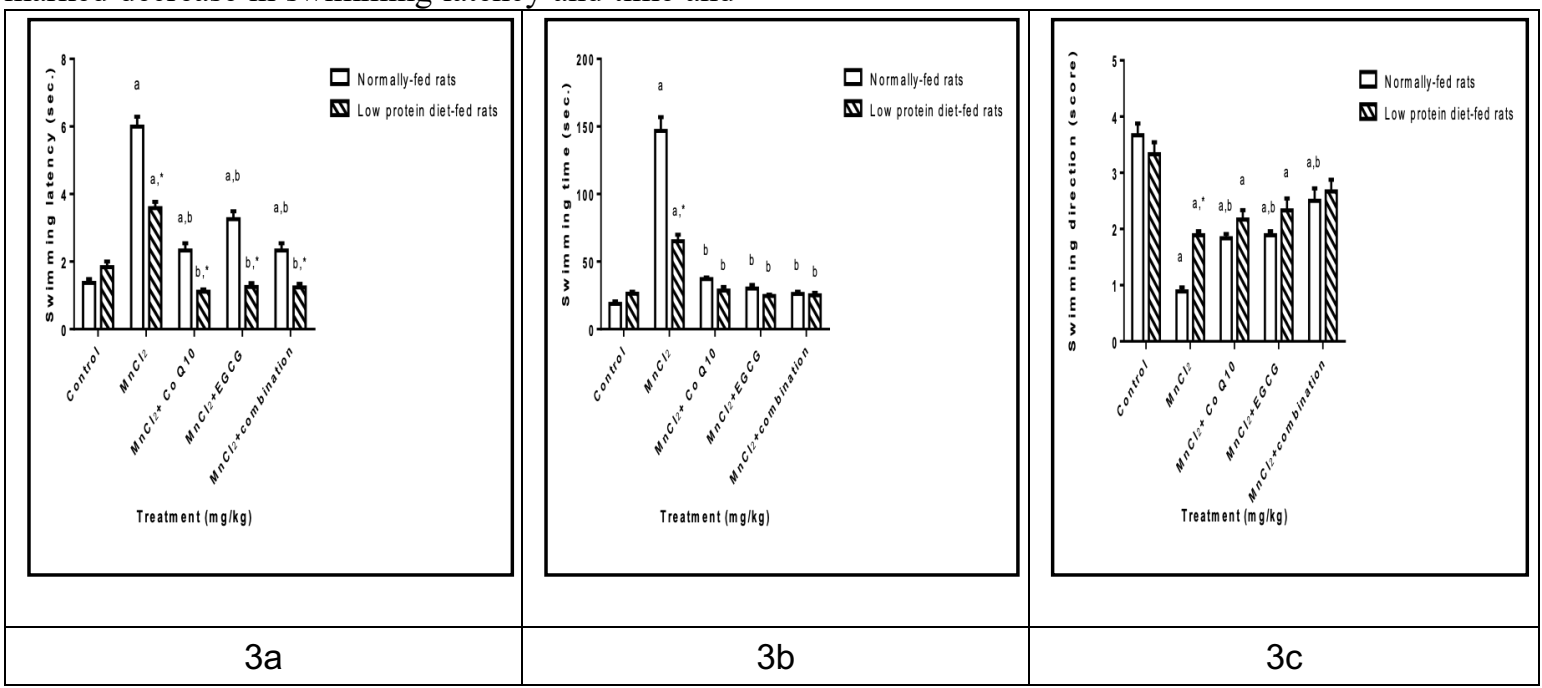

Figure 3: Effect of Co-enzyme Q10 and/or Epigallocatechin-3- gallate on behavioral performance in swimming test (a-swimming latency, b-swimming time, c-direction score) of Manganese-induced parkinsonism in both normally fed and low protein diet-fed rats. Control Animals Received Saline I.P. For 35 Days.

$\mathrm{Mncl}_{2}$ (10 Mg/Kg, I.P.), Co-Enzyme Q10 (200mg/Kg, P.O.), And Egcg (25mg/Kg, I.P.) Were Daily Administered For 35 Days. Data Are Expressed As Mean \pm S.E.M. Of 10 Rats. Analysis Of Data Was Carried Out Using Two-Way Anova Followed By Tukey's Multiple Comparisons Test. A: Significantly Different From The Respective Control Group At $\mathrm{P}<0.05$. B: Significantly Different From The Respective $\mathrm{Mncl}_{2}$ Treated Group At $\mathrm{P}<0.05$. C: Significantly Different From The Respective $\mathrm{Mncl}_{2}$ And Co-Enzyme Q10 Treated Group At $\mathrm{P}<0.05$. D: Significantly Different From The Respective $\mathrm{Mncl}_{2}+$ Egcg Treated Group At $\mathrm{P}<0.05$. *: Significantly Different From The Corresponding Same Group Under Normal Diet Regimen At $\mathrm{P}<0.05$.

\subsubsection{Behavioral Performance Open Field Test:}

In Nf Rats, $\mathrm{Mncl}_{2}$ Caused A Significant

Deterioration In The Motor Performance, Coordination, Vigilance, And Decrease In Locomotor, Emotionality, And Exploratory Activity Manifested As Significant Prolongation Of The Latency And Reduction In Ambulation, Rearing, And Grooming Frequencies By 275.36\%, 89.96\%, $84.83 \%$, And $85.83 \%$ Respectively As Compared To Control Rats. Co Q10, Egcg, And Their Combination Markedly Shortened The Latency By 63.0\%, $56.02 \%$, And 58.02\%, And Increased Ambulation Frequency By $254.70 \%$, 458.46\%, And 242.99\%, Rearing Frequency By 328.52\%, 302.18\%, And $407.63 \%$, And Grooming Frequency By And 155.23\%,210.36\%, And 320.45\% Respectively As Compared To $\mathrm{Mncl}_{2}$ Treated Rats. Intra-Comparing All Treatments Indicated A Non-Significant Alteration In Latency And Rearing Frequency. Egcg Increased The Ambulation By 57.45\% When Compared To Co-Enzyme Q10 Treated Rats But Did
Not Alter Grooming Frequency. While Their Combination Lowered Ambulation Frequency By 38.58\% And When Compared To Egcg Only Treated Rats Without Any Effect When Compared To Co Q10 Treated Rat And Decreased Grooming Frequency By $64.74 \%$ As Compared To Co Q10 Only Treated Rats But Did Not Affect It As Compared To Egcg Alone Treated Rats.

In Low Protein Diet-Fed Rats, $\mathrm{Mncl}_{2}$ Significantly Lengthened The Latency And Lowered Ambulation And Grooming Frequencies By 29.78\%, 45.75\%, And 37.04\% Respectively As Compared T The Control Group Without Any Effect On Rearing Frequency. Co Q10, Egcg, And Their Combination Showed An Obvious Decrease In Latency By 69.74\%, 47.83\%, And 71.11\% Respectively As Compared $\mathrm{To}_{\mathrm{Mncl}}$ Treated Rats. Egcg And Its Combination With Co Q10 Increased Ambulation Frequency By $81.93 \%$ And $81.93 \%$ Respectively As Compared To $\mathrm{Mncl}_{2}$ Treated Rats With No Effect For Co Q10 Alone. The Combination Increased No. 
Of Rearing By 168.89\% As Compared To $\mathrm{Mncl}_{2}$ Only Treated Rats Without Any Significant Effect With Co Q10 Or Egcg. While Co Q10 And Its Combination With Egcg Increased Grooming Frequencies By 135.33 And 164.74\% Respectively As Compared To $\mathrm{Mncl}_{2}$ Treated Rats Without Any Significant Effect With Egcg Alone. IntraComparing All Treatments Indicated A NonSignificant Alteration Regarding Latency. The Combination Of Co Q10 And Egcg Increased Ambulation By 39.83\% As Compared To Co Q10 Only Treated Rats And Increased Rearing Frequency By 49.39\% As Compared To Co Q10 Or Egcg Only Treated Rats And Increased Grooming Frequency By $114.29 \%$ As Compared To Egcg Treated Rats. While Egcg Decreased The Grooming Frequency By $47.50 \%$ As Compared To Co Q10 Treated Rats. Inter-Comparing of The Two Diet Regimens, $\mathrm{Mncl}_{2}$ Treated Rats on Low Protein Diet Showed A Marked Decrease in Latency And Increase In Ambulation, Rearing, And Grooming Frequencies By 27.31\%, 213.18\%, 338.41\%, And $155.23 \%$ Respectively As Compared To The Corresponding Nf Group. Similarly, Co-Treatment With Co Q10 And Egcg Increased Ambulation, Rearing, And Grooming Frequencies By 81.52\%, $57.15 \%$, And $60.70 \%$ Respectively As Compared To The Corresponding Nf Group. Co Q10 Increased Grooming Frequency By 135.33\% As Compared To The Corresponding Nf Group. On The Other Hand, The Control Group On A Low Protein Diet Showed An Obvious Increase In Latency And Decrease In Ambulation, Rearing, And Grooming Frequencies By $110.23 \%$, 42.05\%, 55\%, And 42.55\% When Compared To The Corresponding Nf Group. While Other Treatments Did Not Show Any Significant Alteration When Compared To Their Corresponding Nf Groups (Figure 4 A, B, C, D).

\subsubsection{Working Memory Performance In Y-Maze Test: \\ In Nf Rats, $\mathrm{Mncl}_{2}$ Revealed A Short-Term} Memory Deficit, Indicated By A Marked Drop In The Percentage Of Spontaneous Alternation By $39.20 \%$ As Compared To The Control Rats. Co Q10, Egcg, And Their Combination Markedly Increased It By 36.24\%, 40.67\%, And 50.30\% Respectively As Compared $\mathrm{To}_{\mathrm{Mncl}}$ Alone Treated Rats. IntraComparing The Two Treatment Regimens And Their Combination, The Results Showed A NonSignificant Alteration.

In Low Protein Diet-Fed Rats, $\mathrm{Mncl}_{2} \mathrm{Did}$ Not Significantly Alter \% Of Spontaneous Alteration When Compared To The Control Group. Co Q10, Egcg, And Their Combination Increased \% Of Spontaneous Alteration By 31.36\%, 24.48\%, And
23.10\% Respectively As Compared To $\mathrm{Mncl}_{2}$ Treated Rats. Intra-Comparing All Treatments, The Results Indicated A Non-Significant Alteration. Inter-Comparing Of The Two Diet Regimens, $\mathrm{Mncl}_{2}$ Treated Rats On A Low Protein Diet Showed A Marked Increase In \%. Of Spontaneous Alteration By $20.71 \%$ As Compared To The Corresponding Nf Group. Similarly, Co Q10 Increased It By $16.38 \%$ As Compared To The Corresponding Nf Group. While Control Group On A Low Protein Diet Showed An Obvious Decrease In \% Of Spontaneous Alteration By 16.27\% When Compared To The Corresponding Nf Group. On The Other Hand, Egcg And Its Combination With Co Q10 Did Not Show Any Significant Alteration When Compared To Their Corresponding Nf Group (Figure 5).

\subsection{Biochemical Parameter:}

\subsubsection{Striatal Monoamines' Content}

In Nf Rats, $\mathrm{Mncl}_{2}$ Significantly Decreased Da, 5-Ht, And Ne Content By 86.42\%, 86.56\%, And $88.40 \%$ Respectively As Compared To Control Rats. Co Q10, Egcg, And Their Combination Increased Da Content By $130.07 \%$, 264.22\%, And 374.78\% Respectively, 5-Ht Content By 148.48\%, 342.24\%, And 483.68\% Respectively, And Ne Content By $181.33 \%$, 318.85\%, And 588.15\% Respectively As Compared To $\mathrm{Mncl}_{2}$ Alone Treated Rats. IntraComparing Of All Treatments Egcg Increased Da, 5$\mathrm{Ht}$, And $\mathrm{Ne}$ Content By 58.31\%, 77.98\%, And 48.88\% Respectively As Compared To Co Q10 Treated Rats. While Co-Administration Of Both Showed An Obvious Increase In $\mathrm{Da}, 5-\mathrm{Ht}$, And $\mathrm{Ne}$ Content By 106.36\%, 134.91\%, And 144.61\% Respectively As Compared To Co Q10 Only Treated Rats And By 30.36\%, 31.98\%, And 64.30\% Respectively As Compared To Egcg Only Treated Rats.

Inter-comparing of the two diet regimens, $\mathrm{MnCl}_{2}$ treated rats, on a low protein diet, did not show marked alteration in DA content but increased 5-HT and NE content by $80.50 \%$ and $100.54 \%$ as compared to the corresponding NF group. While administration of Co Q10, EGCG, and their combination showed an increase in DA content by $204.60 \%, 109.15 \%$, and $88.02 \%$ respectively, 5-HT content by $162.26 \%, \quad 60.96 \%$, and $29.05 \%$ respectively, and NE content by $27.63 \%, 24.30 \%$, and $8.71 \%$ respectively as compared to their corresponding NF group. On the other hand, the control group on a low protein diet showed an obvious decrease in DA, 5-HT, and NE content by $25.61 \%, 32.04 \%$, and $53.48 \%$ respectively as compared to the corresponding NF group (Figure 6 $a, b, c)$. 


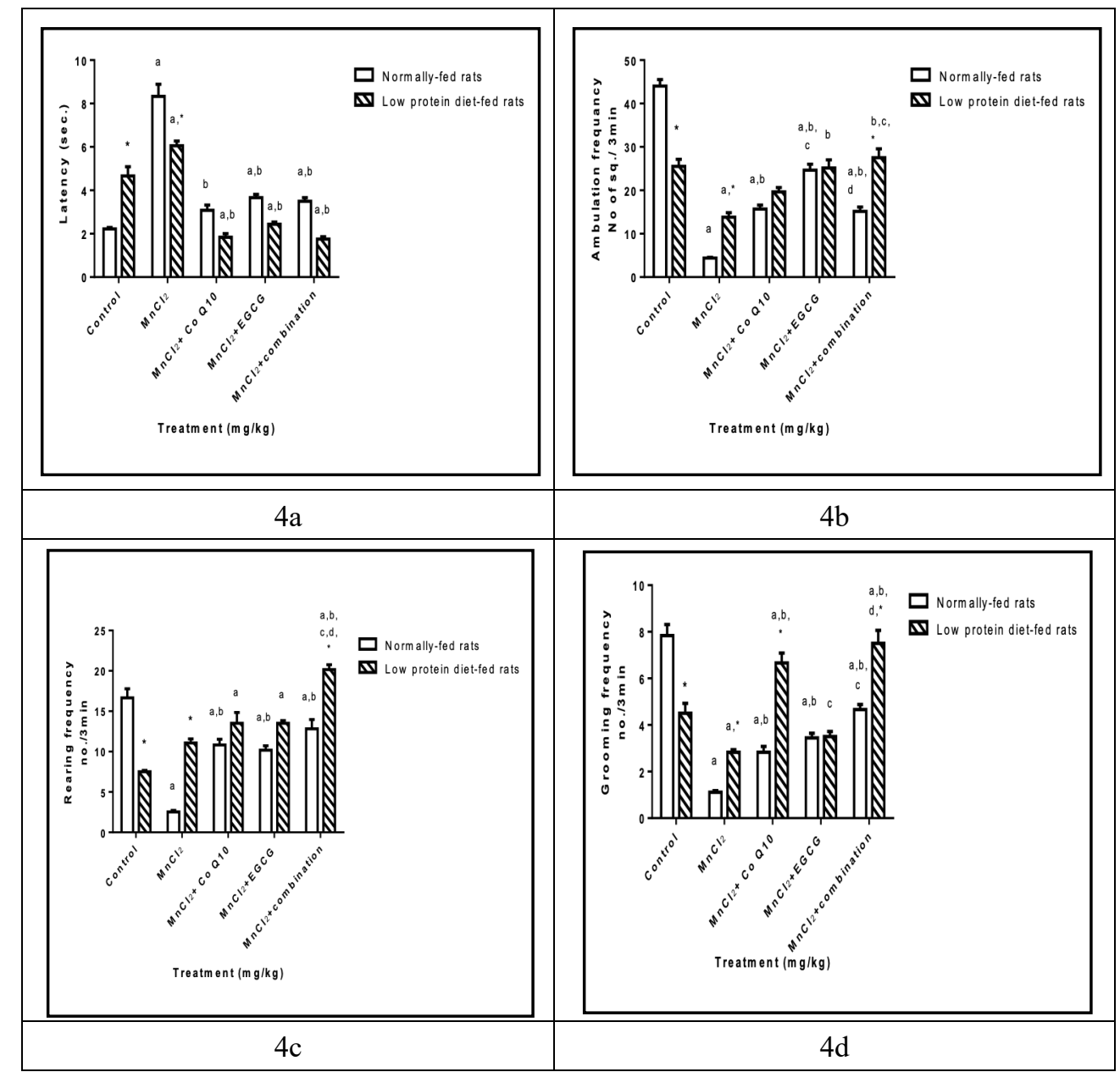

Figure 4: Effect Of Co-Enzyme Q10 And/Or Epigallocatechin-3- Gallate On Behavioral Performance In The Open Field Test (A-Latency Time, B-Ambulation Frequency, C-Rearing Frequency, D-Grooming Frequency) Of Manganese-Induced Parkinsonism In Both Normally Fed And Low Protein Diet-Fed Rats. Control Animals Received Saline I.P. For 35 Days. $\mathrm{Mncl}_{2}$ (10 Mg/Kg, I.P.), Co-Enzyme Q10 (200mg/Kg, P.O.), And Egcg (25mg/Kg, I.P.) Were Daily Administered For 35 Days. Data Are Expressed As Mean \pm S.E.M. Of 10 Rats. Analysis Of Data Was Carried Out Using Two-Way Anova Followed By Tukey's Multiple Comparisons Test. A: Significantly Different From The Respective Control Group At $\mathrm{P}<0.05$. B: Significantly Different From The Respective $\mathrm{Mncl}_{2}$ Treated Group At $\mathrm{P}<0.05$. C: Significantly Different From The Respective $\mathrm{Mncl}_{2}$ And Co-Enzyme Q10 Treated Group At $\mathrm{P}<0.05$. D: Significantly Different From The Respective $\mathrm{Mncl}_{2}+$ Egcg Treated Group At $\mathrm{P}<0.05$.*: Significantly Different From The Corresponding Same Group Under Normal Diet Regimen At $\mathrm{P}<0.05$.

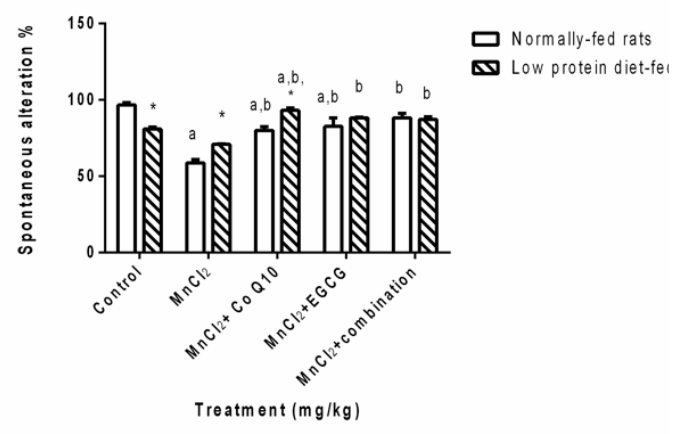

Figure 5: Effect of Co-enzyme Q10 and/or Epigallocatechin-3- gallate on the working memory performance of Manganese-induced parkinsonism in both normally fed and low protein diet-fed rats in $\mathrm{Y}$ maze test.

Control animals received saline I.P. for 35 days. $\mathrm{MnCl}_{2}(10$ $\mathrm{mg} / \mathrm{kg}$, I.P.), Co-enzyme Q10 (200mg/kg, P.O.), and EGCG $(25 \mathrm{mg} / \mathrm{kg}$, I.P.) were daily administered for 35 days. Data are expressed as mean \pm S.E.M. of 10 rats. Analysis of data was carried out using two-way ANOVA followed by Tukey's multiple comparisons test. a: significantly different from the respective control group at $\mathrm{p}<0.05$. b: significantly different from the respective $\mathrm{MnCl}_{2}$ treated group at $\mathrm{p}<0.05$. *: significantly different from the corresponding same group under normal diet regimen at $\mathrm{p}<0.05$. 


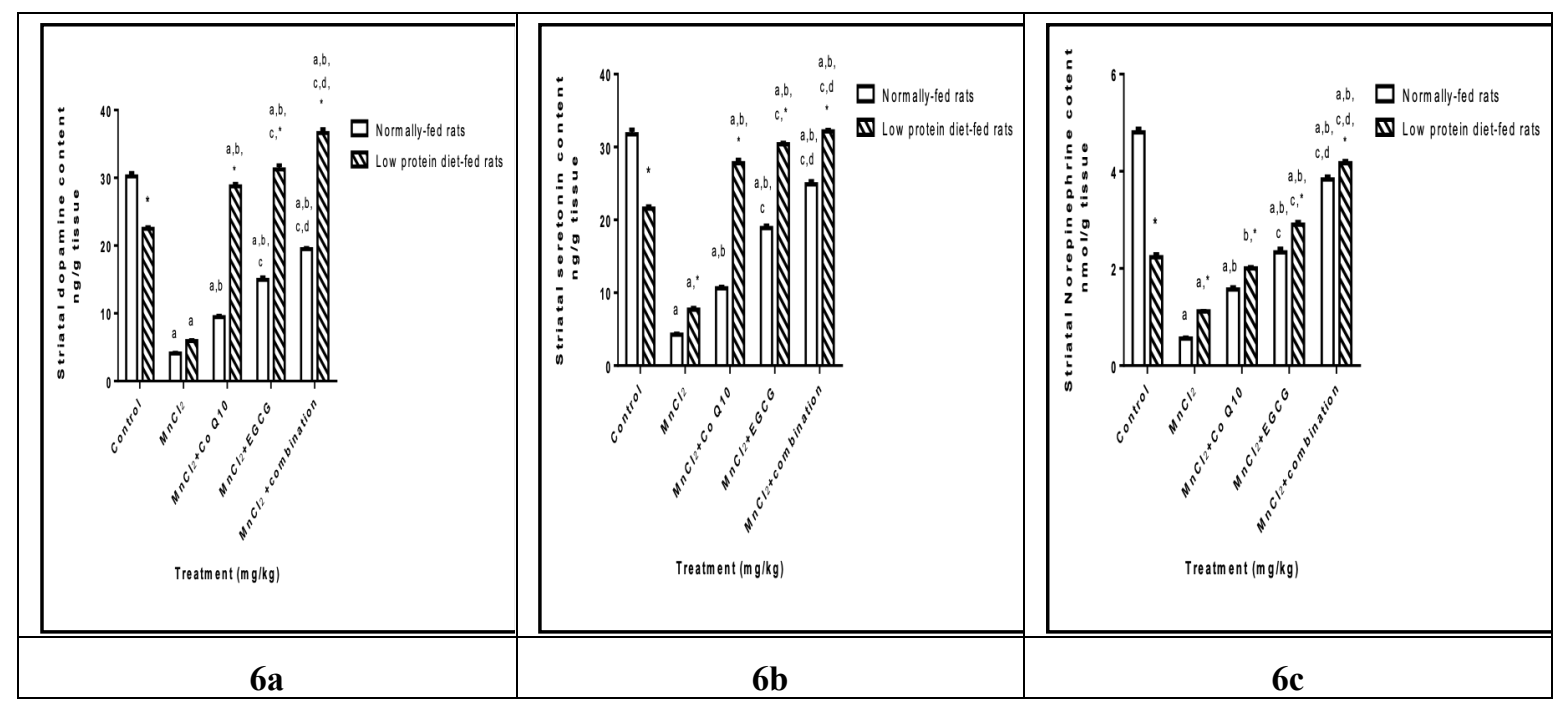

Figure 6: Effect of Co-enzyme Q10 and/or Epigallocatechin-3- gallate on striatal monoamine content (a-dopamine, bserotonin, c-Norepinephrine) of Manganese-induced parkinsonism in both normally fed and low protein diet-fed rats.

Control animals received saline I.P. for 35 days. $\mathrm{MnCl}_{2}$ (10 mg/kg, I.P.), Co-enzyme Q10 (200mg/kg, P.O.), and EGCG $(25 \mathrm{mg} / \mathrm{kg}$, I.P.) were daily administered for 35 days. Data are expressed as mean \pm S.E.M. of 8 rats. Analysis of data was carried out using two-way ANOVA followed by Tukey's multiple comparisons test. a: significantly different from the respective control group at $\mathrm{p}<0.05$. b: significantly different from the respective $\mathrm{MnCl}_{2}$ treated group at $\mathrm{p}<0.05$. c: significantly different from the respective $\mathrm{MnCl}_{2}$ and Co-enzyme Q10 treated group at $\mathrm{p}<0.05$. d: significantly different from the respective $\mathrm{MnCl}_{2}+$ EGCG treated group at $\mathrm{p}<0.05$. *: significantly different from the corresponding same group under normal diet regimen at $\mathrm{p}<0.05$.

\subsubsection{Striatal Oxidative Stress Biomarkers:}

In Nf Rats, $\mathrm{Mncl}_{2}$ Produced A State Of Oxidative Stress Revealed By A Significant Decline In Striatal Sod And Tac Along With A Significant Elevation In Striatal Mda Level Activity By $92.40 \%$, $87.86 \%$, And $1485.88 \%$ Respectively As Compared With The Control Rats. Co Q10, Egcg, And Their Combination Increased The Sod By $832.80 \%$, $1021.21 \%$, And 1198\% Respectively As Compared To $\mathrm{Mncl}_{2}$ Alone Treated Rats, Increased Tac Level By $463.55 \%$, 582.49\%, And 672.35\% As Compared To $\mathrm{Mncl}_{2}$ Alone Treated Rats And Decreased Mda By $64.27 \%$, 78.98\%, And 87.07\% Respectively As Compared To $\mathrm{Mncl}_{2}$ Treated Rats. Intra-Comparing Of All Treatments Egcg Increased The Sod Content And Tac And Decreased Mda Level By 20.20\%, $21.10 \%$, And $41.17 \%$ As Compared To Co Q10 Treated Rats. While Co-Administration Of Both Markedly Increased Sod Content And Tac And Reduced Mda Content By 39.15\%, 37.05\%, And $63.80 \%$ As Compared To Co Q10 Only Treated Rats And By $15.77 \%, 13.17 \%$, And 38.47\% Respectively As Compared To Egcg Only Treated Rats.

In Low Protein Diet-Fed Rats, $\mathrm{Mncl}_{2}$ Significantly Decreased Sod Content And Tac And Increased Mda Content By 79.04\%, 70.63\%, And $117.86 \%$ Respectively When Compared To The Control Group. Co Q10, Egcg, And Their Combination Increased Sod Content By 538.66\%,
$637.25 \%$, And 752.98\% Respectively, Increased Tac By 372.39\%, 427.61\%, And 549.53\% Respectively, And Reduced Mda Level By 63.85\%, 80.59\%, And $89.47 \%$ Respectively As Compared $\mathrm{Mncl}_{2}$ Treated Rats. Intra-Comparing Of All Treatments Egcg Significantly Increased Sod Content And Tac And Reduced Mda By 15.44\%, 11.69\%, And 46.30\% Respectively As Compared To Co Q10 Only Treated Rats. While Co-Administration Of Both Markedly Increased Sod Content And Tac And Reduced Mda Level By 33.56\%, 37.50\%And 70.88\% Respectively As Compared To Co Q10 Only Treated Rats And By $15.70 \%$, 23.11\%, And 45.77\% Respectively As Compared To Egcg Only Treated Rats.

Inter-Comparing Of The Two Diet Regimens, $\mathrm{Mncl}_{2}$ Treated Rats, On A Low Protein Diet, Did Not Record A Significant Alteration In Sod Content Or Tac But It Showed A Significant Reduction In Mda Content By 6.31\% As Compared To The Corresponding Nf Group. Co Q10, Egcg, And The Combination Of Both Showed An Increase In Tac By 18.95\%, 9.7\%, And 19.34\% As Compared To Their Corresponding Nf Group Respectively But Did Not Show Any Significant Alteration Regarding Mda Level. While Co Q10 And The Combination Showed An Increase In Sod Content By $11.47 \%$ And 6.99\% As Compared To Their Corresponding Nf Group Respectively. On The Other Hand, The Control Group On A Low Protein Diet Showed An 


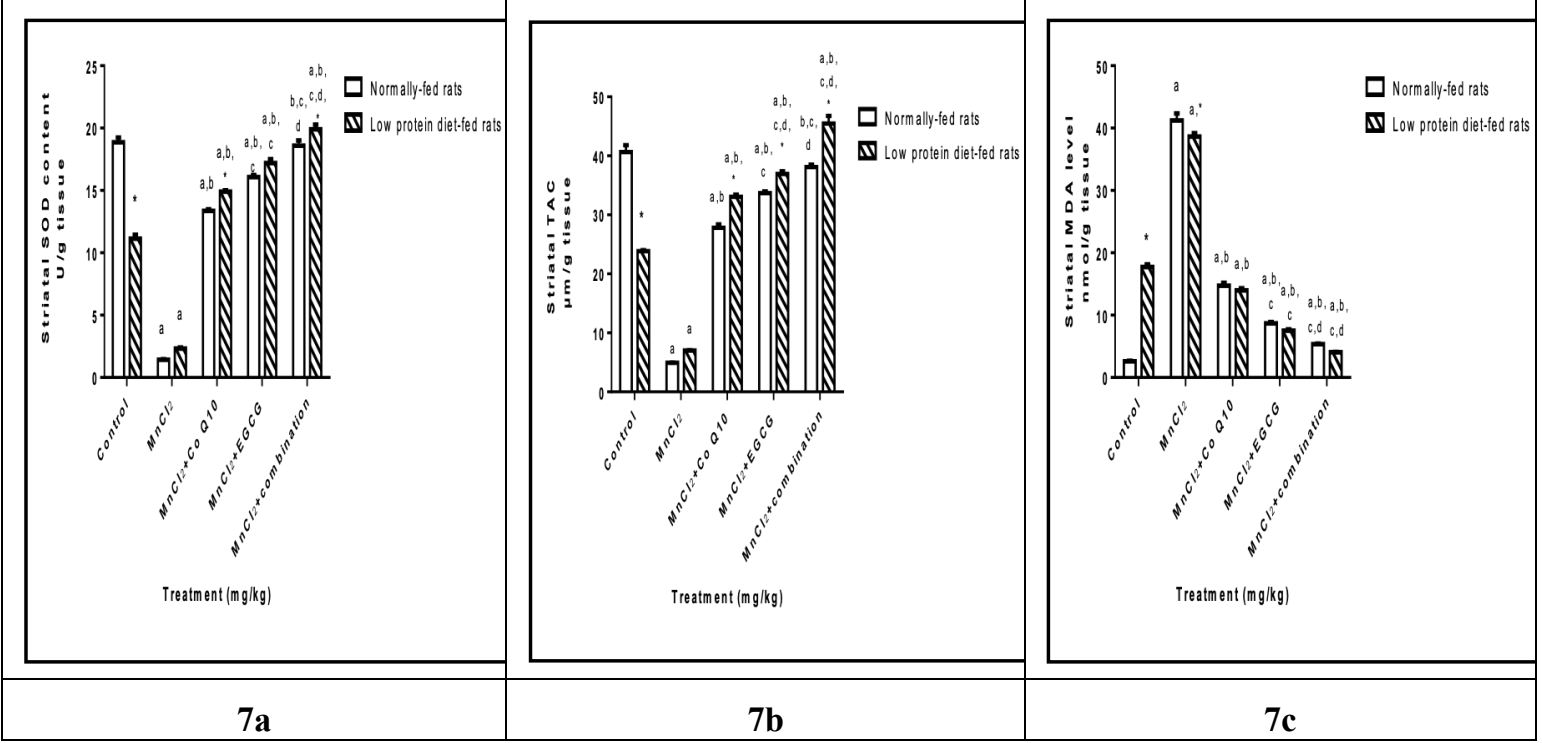

Figure 7: Effect of Co-enzyme Q10 and/or Epigallocatechin-3- gallate on striatal oxidative stress biomarkers (a-superoxide dismutase, b- total antioxidant capacity, c- malondialdehyde content) of Manganese-induced parkinsonism in both normally fed and low protein diet-fed rats. Control animals received saline I.P. for 35 days. $\mathrm{MnCl}_{2}$ (10 mg/kg, I.P.), Co-enzyme Q10 $(200 \mathrm{mg} / \mathrm{kg}$, P.O.), and EGCG (25mg/kg, I.P.) were daily administered for 35 days. Data are expressed as mean \pm S.E.M. of 8 rats. Analysis of data was carried out using two-way ANOVA followed by Tukey's multiple comparisons test. a: significantly different from the respective control group at $\mathrm{p}<0.05$. b: significantly different from the respective $\mathrm{MnCl}_{2}$ treated group at $\mathrm{p}<0.05$. c: significantly different from the respective $\mathrm{MnCl}_{2}$ and Co-enzyme Q10 treated group at $\mathrm{p}<0.05$. $\mathrm{d}$ : significantly different from the respective $\mathrm{MnCl}_{2}+$ EGCG treated group at $\mathrm{p}<0.05$. *: significantly different from the corresponding same group under normal diet regimen at $\mathrm{p}<0.05$.

\subsubsection{Striatal inflammatory biomarkers:}

In $\mathrm{NF}$ rats, $\mathrm{MnCl}_{2}$ triggered inflammation via elevating the TNF- $\alpha$ and COX-II content by $923.52 \%, 1170.51 \%$ respectively as compared to the control rats. Co Q10, EGCG, and their combination decreased TNF- $\alpha$ content by $66.94 \%, 77.96 \%$, and $84.82 \%$ respectively, and decreased COX-II content by $65.07 \%, 75.15 \%$, and $80.81 \%$ respectively as compared to $\mathrm{MnCl}_{2}$ alone treated rats. Intracomparing of all treatments EGCG decreased TNF- $\alpha$ and COX-II content by $33.33 \%$ and $28.88 \%$ respectively as compared to Co Q10 treated rats. While Co-administration of both markedly reduced TNF- $\alpha$ and COX-II content by $54.08 \%$ and $45.07 \%$ respectively as compared to Co Q10 only treated rats and by $31.13 \%$ and $22.77 \%$ as compared to EGCG only treated rats.

In low protein diet-fed rats, $\mathrm{MnCl}_{2}$ significantly increased TNF- $\alpha$ and COX-II content by $82.01 \%$ and $25.88 \%$ as compared to the control group. Co Q10, EGCG, and their combination reduced TNF- $\alpha$ content by $70.49 \%, 78.20 \%$, and $87.93 \%$ respectively, and reduced COX-II content by $65.89 \%, 81.78 \%$, and $91.59 \%$ respectively as compared to $\mathrm{MnCl}_{2}$ treated rats. Intra-comparing of all treatments EGCG significantly decreased TNF$\alpha$ and COX-II content by $26.11 \%$ and $46.58 \%$ respectively as compared to Co Q10 only treated rats. Co-administration of Co Q10 and EGCG markedly reduced TNF- $\alpha$ and COX-II content by $59.11 \%$ and $75.34 \%$ respectively as compared to Co Q10 only treated rats and by $44.66 \%$ and $53.85 \%$ respectively as compared to EGCG only treated rats.

Inter-comparing of the two diet regimens, $\mathrm{MnCl}_{2}$ treated rats on low protein diet showed a significant reduction in TNF- $\alpha$ and COX-II content by $28.48 \%$ and $21.03 \%$ respectively as compared to the corresponding NF group. While administration of Co Q10, EGCG, and their combination recorded a reduction in TNF- $\alpha$ content by $36.16 \%, 29.25 \%$, and $43.15 \%$ respectively, and a significant reduction in COX-II by $22.89 \%, 42.08 \%$, and $65.38 \%$ respectively when compared to their corresponding NF group. On the other hand, the control group on a low protein diet showed an obvious increase in TNF$\alpha$ and COX-II content by $302.17 \%$, and $697 \%$ when compared to the corresponding NF group (Figure 8 $\mathrm{a}, \mathrm{b})$. 


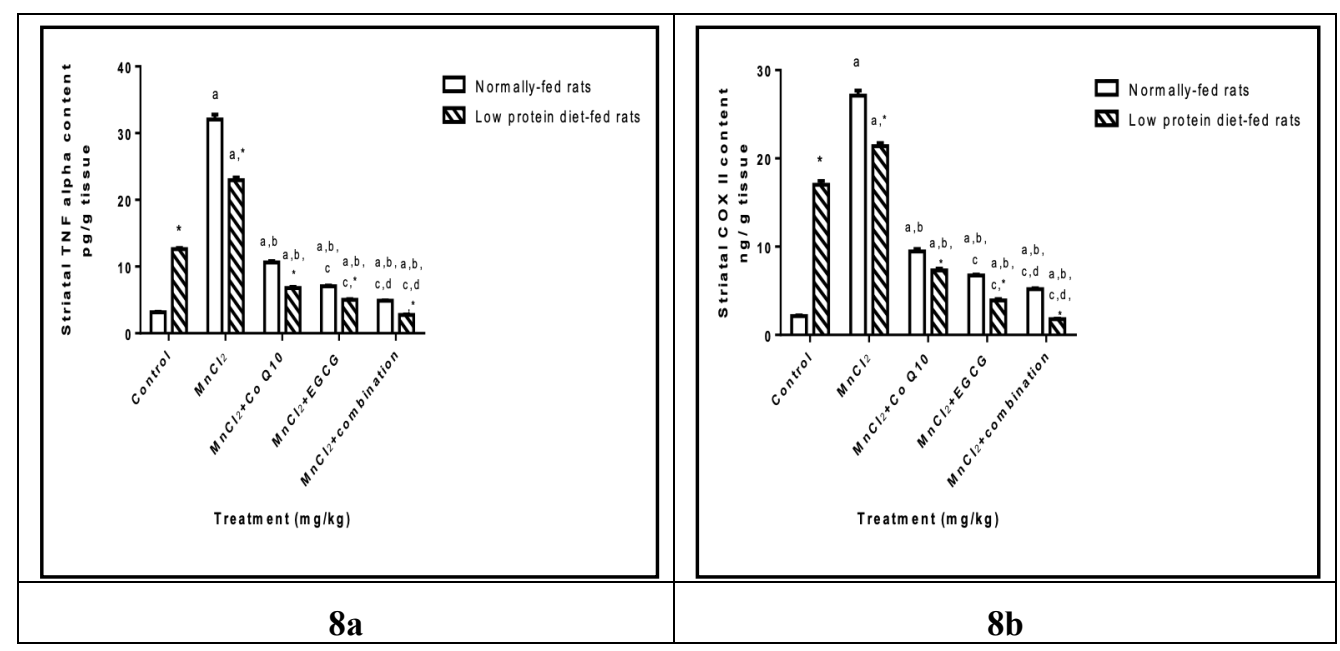

Figure 8: Effect of Co-enzyme Q10 and/or Epigallocatechin-3- gallate on striatal anti-inflammatory biomarkers (a-tumor necrosis factor, b- cyclooxygenase II) of Manganese-induced parkinsonism in both normally fed and low protein diet-fed rats. Control animals received saline I.P. for 35 days. $\mathrm{MnCl}_{2}(10 \mathrm{mg} / \mathrm{kg}$, I.P.), Co-enzyme Q10 (200mg/kg, P.O.), and EGCG $(25 \mathrm{mg} / \mathrm{kg}$, I.P.) were daily administered for 35 days.Data are expressed as mean \pm S.E.M. of 8 rats. Analysis of data was carried out using two-way ANOVA followed by Tukey's multiple comparisons test. a: significantly different from the respective control group at $\mathrm{p}<0.05$. b: significantly different from the respective $\mathrm{MnCl}_{2}$ treated group at $\mathrm{p}<0.05$. c: significantly different from the respective $\mathrm{MnCl}_{2}$ and Co-enzyme Q10 treated group at $\mathrm{p}<0.05$. d: significantly different from the respective $\mathrm{MnCl}_{2}+\mathrm{EGCG}$ treated group at $\mathrm{p}<0.05$. *: significantly different from the corresponding same group under normal diet regimen at $\mathrm{p}<0.05$.

\subsection{4.}

Factor:

In Nf Rats, Mncl2 Significantly Reduced Bdnf Content By $80.22 \%$ As Compared To Control Rats. Co Q10, Egcg, And Their Combination Increased Bdnf Content By 70.36\%, 139.23\%, And 192.61\% Respectively As Compared To Mncl2 Alone Treated Rats. IntraComparing Of All Treatments Egcg Increased Bdnf Content By $40.42 \%$ As Compared To Co Q10 Treated Rats. While Co-Administration Of Both Markedly Increased Bdnf Content By $71.76 \%$ And 22.32\% As Compared To Co-Enzyme Q10 Only Treated Rats And Egcg Only Treated Rats Respectively.

In Low Protein Diet-Fed Rats, Mncl2 Significantly Decreased Bdnf Content By 55.84\% As Compared To The Control Group. Co Q10, Egcg, And Their Combination Increased Bdnf Content By 99.90\%, 213.27\%, And 236.58\% Respectively As Compared To Mncl2 Treated Rats. Intra-Comparing Of All Treatments Egcg Significantly Increased Bdnf Content By $56.71 \%$ As Compared To Co Q10 Only Treated Rats. While CoAdministration Of Both Showed An Obvious Increase In Bdnf Content By $68.37 \%$ As Compared To Co Q10 Only Treated Rats And A Non-Significant Alteration When Compared To Egcg.

Inter-Comparing Of The Two Diet Regimens, Mncl2 Treated Rats, On A Low Protein Diet, Did Not Record A Significant Change In Bdnf Content When Compared To The Corresponding Nf Group. Also, Treatment With Co Q10 Or The Combination Of Both Did Not Show A Significant Alteration In Bdnf When Compared To Their Corresponding Nf Group. While Administration Of Egcg
Recorded A Significant Increase In Bdnf Content By $17.13 \%$ As Compared To The Corresponding Nf Group. On The Other Hand, The Control Group On A Low Protein Diet Showed An Obvious Reduction In Bdnf Content By 59.93\% When Compared To The Corresponding Nf Group (Figure 9).

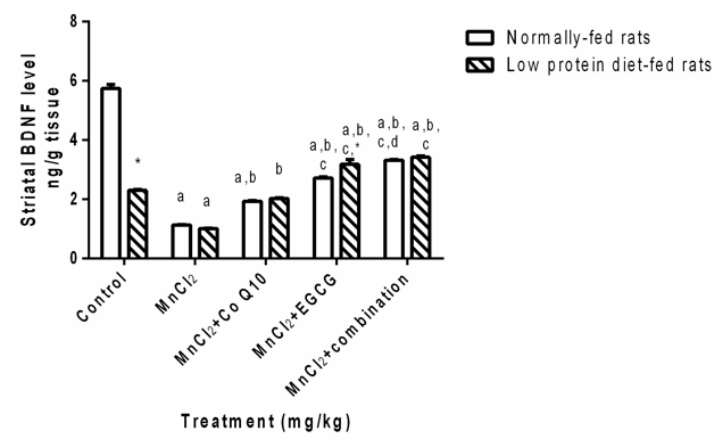

Figure 9: Effect Of Co-Enzyme Q10 And/Or Epigallocatechin-3- Gallate On The Striatal Brain-Derived Neurotrophic Factor Of Manganese-Induced Parkinsonism In Both Normally Fed And Low Protein Diet-Fed Rats.

Control Animals Received Saline I.P. For 35 Days. $\mathrm{Mncl}_{2}$ (10 Mg/Kg, I.P.), Co-Enzyme Q10 (200mg/Kg, P.O.), And Egcg $(25 \mathrm{mg} / \mathrm{Kg}$, I.P.) Were Daily Administered For 35 Days. Data Are Expressed As Mean \pm S.E.M. Of 8 Rats. Analysis Of Data Was Carried Out Using Two-Way Anova Followed By Tukey's Multiple Comparisons Test. A: Significantly Different From The Respective Control Group At $\mathrm{P}<0.05$. B: Significantly Different From The Respective $\mathrm{Mncl}_{2}$ Treated Group At $\mathrm{P}<0.05$. C: Significantly Different From The Respective $\mathrm{Mncl}_{2}$ And 
Co-Enzyme Q10 Treated Group At $\mathrm{P}<0.05$. D: Significantly Different From The Respective $\mathrm{Mncl}_{2}+$ Egcg Treated Group At $\mathrm{P}<0.05$. *: Significantly Different From The Corresponding Same Group Under Normal Diet Regimen At $\mathrm{P}<0.05$.

\subsubsection{Striatal Complex-I content:}

In NF rats, striatal mitochondrial complex-I content was markedly decreased following the administration of $\mathrm{MnCl}_{2}$ by $82.19 \%$ as compared to control rats. Co Q10, EGCG, and their combination increased Complex-I content by $326.14 \%, 359.30 \%$, and $301.29 \%$ respectively as compared to $\mathrm{MnCl}_{2}$ alone treated rats. Intra-comparing of all treatments EGCG decreased the Complex-I content by $15.68 \%$ as compared to Co Q10 treated rats. While Coadministration of both reduced Complex-I content by $11.69 \%$ as compared to EGCG but did not affect it as compared to Co Q10 only treated rats.

In low protein diet-fed rats, $\mathrm{MnCl}_{2}$ significantly decreased Complex-I content by $30.49 \%$ as compared to the control group. Co Q10, EGCG, and their combination increased Complex-I content by $50.94 \%, \quad 26.36 \%$, and $43.87 \%$ respectively as compared to $\mathrm{MnCl}_{2}$ treated rats. Intracomparing of all treatments EGCG significantly decreased Complex-I content by $16.28 \%$ as compared to Co Q10 only treated rats. While coadministration of both showed an obvious increase in Complex-I content by $13.86 \%$ as compared to EGCG only treated rats and a non-significant alteration when compared to Co Q10 only treated rats.

Inter-comparing of the two diet regimens, $\mathrm{MnCl}_{2}$ treated rats on a low protein diet recorded a significant increase in Complex-I content by $154.50 \%$ when compared to the corresponding NF group. Co Q10 and EGCG showed a significant decrease in Complex-I by $9.85 \%$ and $10.49 \%$ respectively as compared to their corresponding NF group. Also, the control group on a low protein diet showed an obvious reduction in Complex-I content by $34.79 \%$ when compared to the corresponding NF group. But the combination of Both did not affect it (Figure 10).

Control animals received saline I.P. for 35 days. $\mathrm{MnCl}_{2}(10$ $\mathrm{mg} / \mathrm{kg}$, I.P.), Co-enzyme Q10 (200 $\mathrm{mg} / \mathrm{kg}$, P.O.), and EGCG $(25 \mathrm{mg} / \mathrm{kg}$, I.P.) were daily administered for 35 days. Data are expressed as mean \pm S.E.M. of 8 rats. Analysis of data was carried out using two-way ANOVA followed by Tukey's multiple comparisons test. a: significantly different from the respective control group at $p<0.05$. b: significantly different from the respective $\mathrm{MnCl}_{2}$ treated group at $\mathrm{p}<0.05$. c: significantly different from the respective $\mathrm{MnCl}_{2}$ and Co-enzyme Q10 treated group at $p<0.05$. d: significantly different from the respective $\mathrm{MnCl}_{2}+\mathrm{EGCG}$ treated group at $\mathrm{p}<0.05$. *: significantly different from the corresponding same group under normal diet regimen at $\mathrm{p}<0.05$.

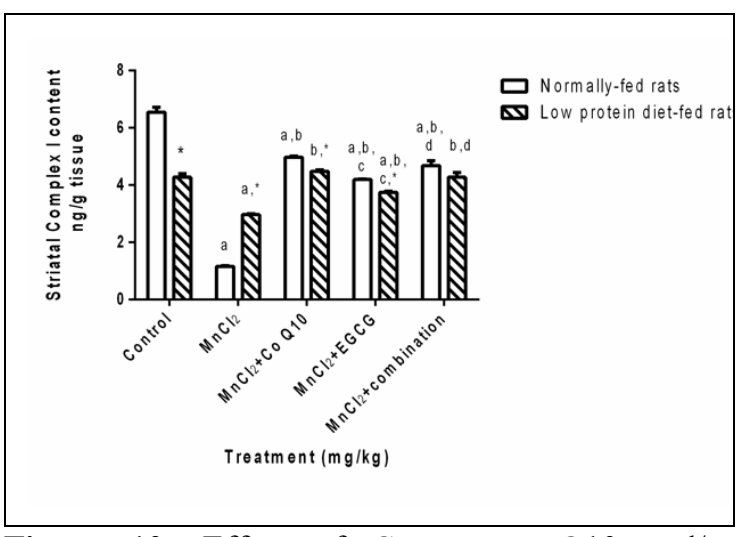

Figure 10: Effect of Co-enzyme Q10 and/or Epigallocatechin-3- gallate on striatal Complex-I content of Manganese-induced parkinsonism in both normally fed and low protein diet-fed rats.

\subsection{Histopathological Examination Of Brain} Tissue:

Brain Sections From All The Groups Were Stained With H \& E And Examined; The Effect Of Treatments On Different Brain Areas Is Shown In Figs. 11, 12, 13, And 14.

In Nf Rats, No Histopathological Alteration Found In The Cerebral Cortex, And Covering Meninges, Hippocampus (Subiculum, Fascia Dentate, And Hilus), And Striatum Were Recorded In The Brain Tissue Of The Control Group (As Shown In Fig.11a, 12a, 13a, 14a).

$\mathrm{Mncl}_{2}$ Caused Nuclear Pyknosis And Degeneration Noticed In The Neurons Of The Cerebral Cortex, Subiculum, Fascia Dentate And Hilus Of The Hippocampus (As Shown In Fig.11b, 12b, 13b) And Formation Of Multiple Focal Eosinophilic Plagues, Nuclear Pyknosis, And Degeneration In The Neurons, Vacuolization Of The Matrix, Focal Gliosis, Congestion In The Blood Vessels And Intracytoplasmic Lewy Body In Some Cells (As Shown In Fig.14b) Of The Striatum

Co Q10 Result In Nuclear Pyknosis And Degeneration In The Neurons Of The Fascia Dentate And Hilus Of The Hippocampus (As Shown In Fig.13c) Associated With Multiple Focal Eosinophilic Plagues Formation And Intracytoplasmic Lewy Bodies In Some Neurons (As Shown In Fig.14c) Of The Striatum And The Cerebral Cortex And Subiculum Of The Hippocampus Showed Intact Neurons (As Shown In Fig.11c\&12c).

Egcg Resulted In Nuclear Pyknosis And Degeneration In The Neurons Of The Cerebral Cortex (As Shown In Fig.11d), Nuclear Pyknosis And Degeneration In Some Of The Neurons In Fascia Dentate Of The Hippocampus (As Shown In Fig.13d), And A Few Focal Eosinophilic Plagues Formation In The Striatum (As Shown In Fig.14d). While The Neurons In The Subiculum of The Hippocampus Were Normal (As Shown In Fig.12d) 
Co Q10 And Egcg Recorded A Nuclear Pyknosis And Degeneration In Few Neurons Of The Cerebral Cortex (As Shown In Fig.11e), As Well As In The Subiculum Of The Hippocampus (As Shown In Fig.12e) And Congestion In The Blood Vessels Of The Matrix And Nuclear Pyknosis With Degeneration In The Neurons Of The Striatum (As Shown In Fig.14e). While The Neurons In The Fascia Dentate Of The Hippocampus Were Normal (As Shown In Fig.13e).

In Low Protein Diet-Fed Rats, No Histopathological Alteration Was Recorded In The Cerebral Cortex And Covering Meninges, Hippocampus (Subiculum, Fascia Dentate, And Hilus), And Striatum In Brain Tissues Of Control Rats (As Shown In Fig.11f, 12f 13f, 14f).

$\mathrm{Mncl}_{2}$ Resulted In Nuclear Pyknosis And Degeneration In The Neurons Of The Cerebral Cortex (As Shown In Fig.11g), Few Neurons Of The Subiculum (As Shown In Fig.12g), And In Most Of The Neurons Of The Fascia Dentate And Hilus (As Shown In Fig.13g) In The Hippocampus And
Nuclear Pyknosis And Degeneration In The Striatum Neurons (As Shown In Fig.14g).

Co Q10 Caused Nuclear Pyknosis And Degeneration In The Cerebral Cortex Neurons (As Shown In Fig.11h), With Normal Histological Structure In The Subiculum, Fascia Dentate, And Hilus Of The Hippocampus And The Striatum (As Shown In Fig.12h, 13h, 14h).

Egcg Resulted In Nuclear Pyknosis And Degeneration In Some Cerebral Cortex Neurons (As Shown In Fig.11i) And A Few Gliosis In Between The Intact Striatum Neuron (As Shown Infig.14i). With Normal Structure In The Subiculum (As Shown In Fig.12i), And Fascia Dentate (As Shown In Fig.13i) Of The Hippocampus.

Co-Administration Of Both Recorded Nuclear Pyknosis And Degeneration In The Cerebral Cortex Neurons (As Shown In Fig.11j) And Congestion In The Blood Vessels With Diffuse Gliosis In Between The Intact Striatum Neurons (As Shown Infig.14j), Without Any Alteration In Subiculum Neurons, Fascia Dentate And Hilus Of The Hippocampus (As Shown In Fig. 12j \& 13j).
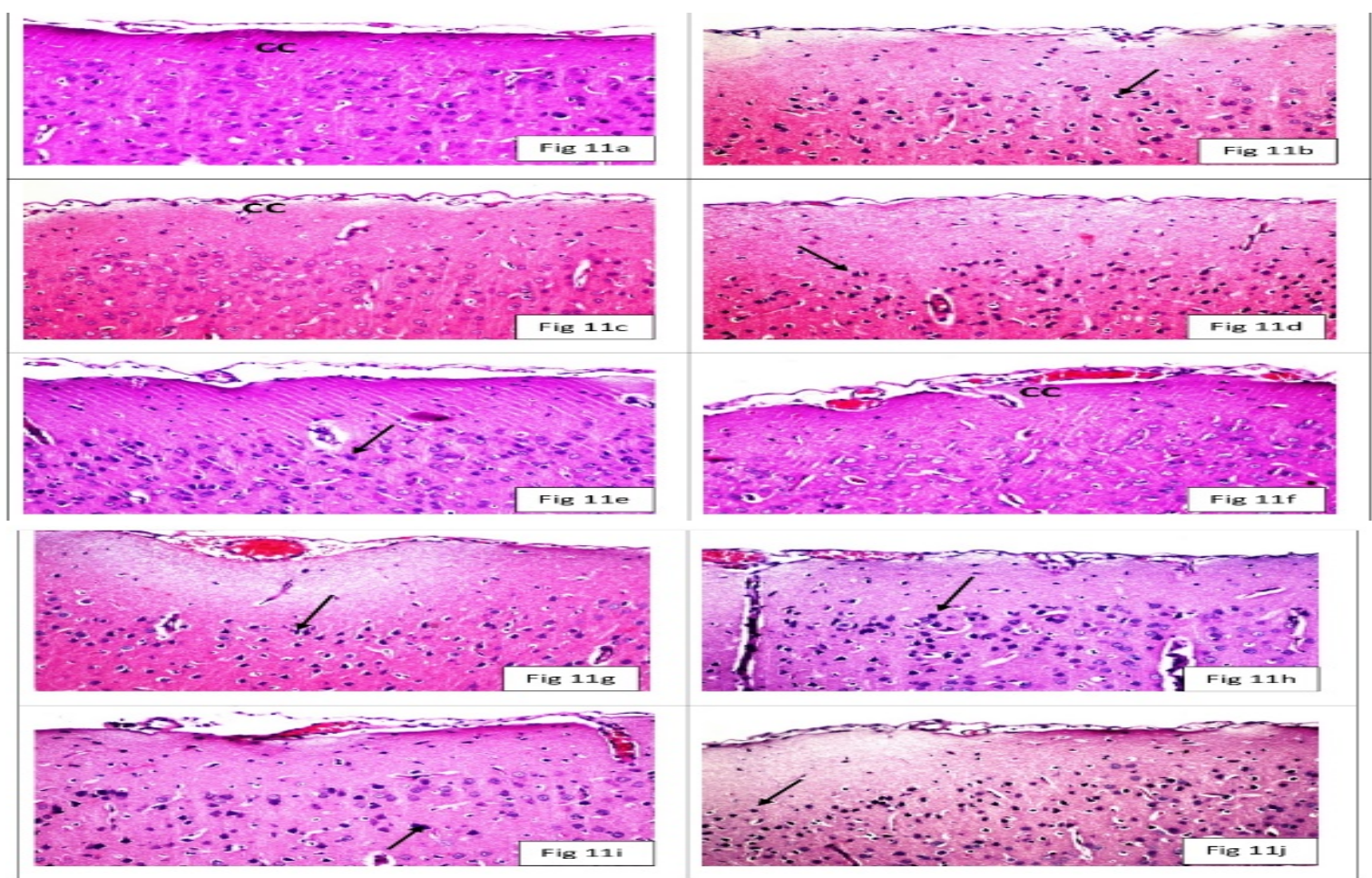

Figure 11 : Representative photomicrographs of the cerebral cortex (cc) and covering meninges from brain sections showing: a- normal histological structure in NF control rats (H\&E 40), b- nuclear pyknosis and degeneration (arrow) in cc

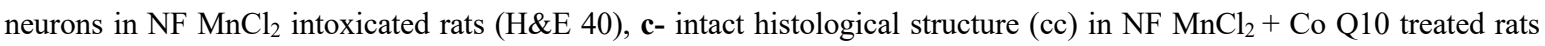
(H\&E 40), d- nuclear pyknosis and degeneration (arrow) in cc neurons in $\mathrm{NF} \mathrm{MnCl}_{2}+\mathrm{EGCG}$ treated rats (H\&E 40), enuclear pyknosis and degeneration (arrow) in few cc neurons in $\mathrm{MnCl}_{2}+$ combination-treated rats (H\&E 40), f- normal histological structure (cc) in low protein diet - fed control rats (H\&E 40), g- nuclear pyknosis and degeneration (arrow) in cc neuron in low protein diet - fed $\mathrm{MnCl}_{2}$ intoxicated rats (H\&E 40), h- nuclear pyknosis and degeneration (arrow) in some cc neurons in low protein diet - fed $\mathrm{MnCl}_{2}+\mathrm{Co} \mathrm{Q} 10$ treated rats. (H\&E 40), i- nuclear pyknosis and degeneration (arrow) 
in some cc neurons in low protein diet - fed $\mathrm{MnCl}_{2}+\mathrm{EGCG}$ treated rats (H\&E 40), $\mathbf{j}$ - nuclear pyknosis and degeneration (arrow) in cc neurons in low protein diet - fed $\mathrm{MnCl}_{2}+$ combination-treated rats ( $\left.\mathrm{H} \& \mathrm{E} 40\right)$.

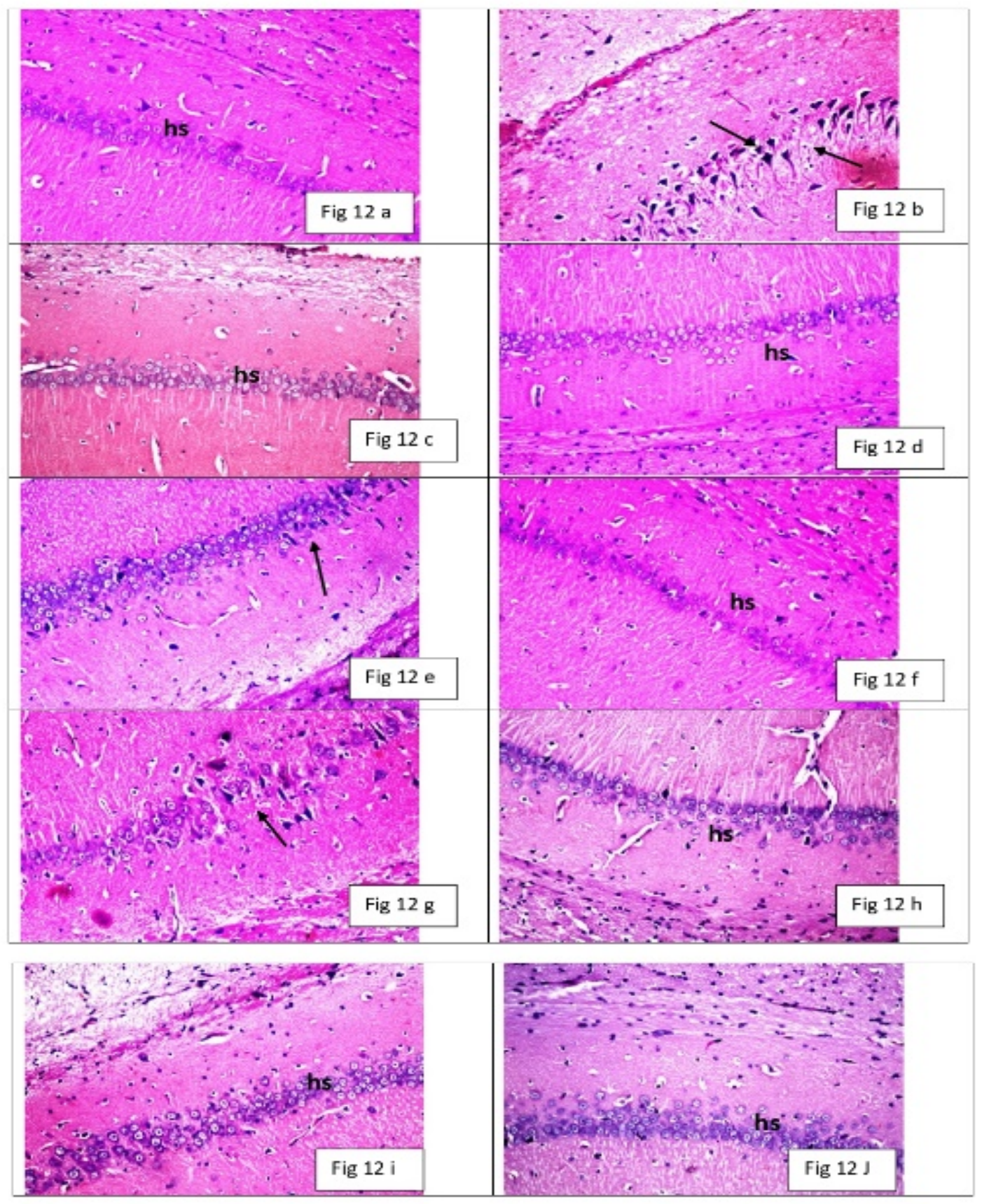

Figure 12: Representative Photomicrographs Of Subiculum Of Hippocampus From Brain Sections Showing: A- Normal Histological Structure Of The Neurons In Nf Control Rats (H\&E 40), B- Nuclear Pyknosis And Degeneration (Arrow) In Neurons In Nf $\mathrm{Mncl}_{2}$ Intoxicated Rats (H\&E 40), C- Intact Histological Structure In Nf $\mathrm{Mncl}_{2}+$ Co Q10 Treated Rats (H\&E 40), D- Intact Histological Structure In Nf $\mathrm{Mncl}_{2}+$ Egcg Treated Rats (H\&E 40), E- Nuclear Pyknosis And Degeneration (Arrow) In Very Few Individual Neurons In Nf Mncl2 + Combination Treated Rats (H\&E 40), F- Normal Histological Structure In Low Protein Diet - Fed Control Rats (H\&E 40), G- Nuclear Pyknosis And Degeneration (Arrow) In Some Few Neurons In Low Protein Diet - Fed Mncl 2 Intoxicated Rats (H\&E 40), H- Intact Histological Structure In Low Protein Diet - Fed $\mathrm{Mncl}_{2}+\mathrm{Co}$ Q10 Treated Rats (H\&E 40), I- Normal Histological Structure In Low Protein Diet Fed $\mathrm{Mncl}_{2}+$ Egcg Treated Rats (H\&E 40), J- Normal Histological Structure In Low Protein Diet - Fed Mncl + + Combination Treated Rats (H\&E 40). 

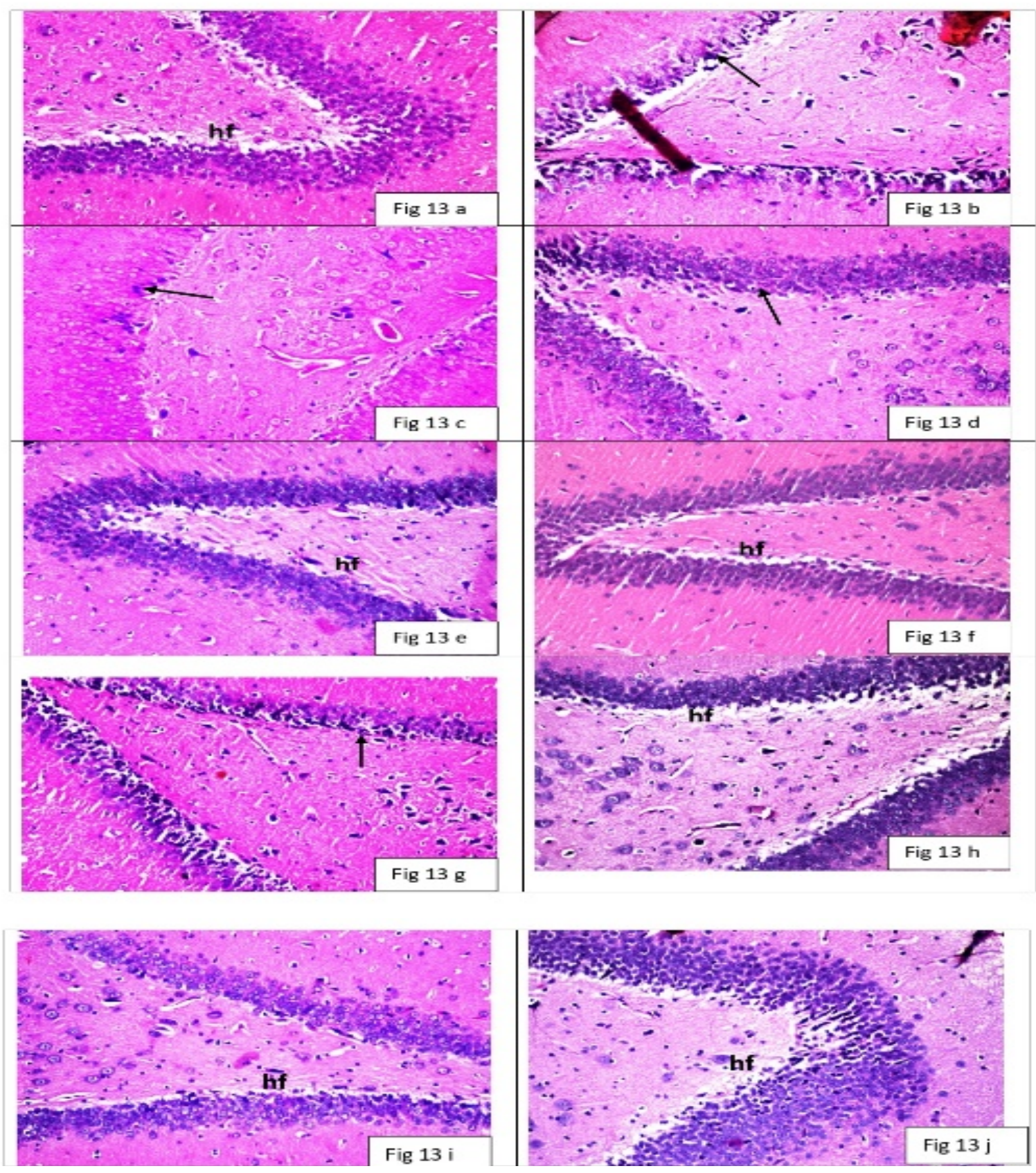

Figure 13: Representative Photomicrographs Of Fascia Dentata (Hf) And Hilus Of Hippocampus From Brain Sections Showing: A- Normal Histological Structure In Nf Control Rats (H\&E 40), B- Nuclear Pyknosis And Degeneration (Arrow) In Nf $\mathrm{Mncl}_{2}$ Intoxicated Rats (H\&E 40), C- Nuclear Pyknosis And Degeneration (Arrow) In Some Neurons In $\mathrm{Nf}_{\mathrm{Mncl}}+$ Co Q10 Treated Rats (H\&E 40), D- Nuclear Pyknosis And Degeneration (Arrow) In Some Neurons In Nf Mncl2 + Egcg Treated Rats (H\&E 40), E- Intact Neurons In Nf Mncl2 + Combination Treated Rats (H\&E 40), F- Normal Histological Structure Of Neurons In Low Protein Diet - Fed Control Rats (H\&E 40), G- Nuclear Pyknosis And Degeneration (Arrow) In Most Of Neurons In Low Protein Diet - Fed Mncl 2 Intoxicated Rats (H\&E 40), H- Normal Histological Structure In Low Protein Diet - Fed $\mathrm{Mncl}_{2}+$ Coq10 Treated Rats (H\&E 40), I- Normal Histological Structure In Low Protein Diet - Fed $\mathrm{Mncl}_{2}+$ Egcg Treated Rats (H\&E 40), J- Normal Histological Structure In Low Protein Diet - Fed $\mathrm{Mncl}_{2}+\mathrm{Combination}$ Treated Rat (H\&E 40) 

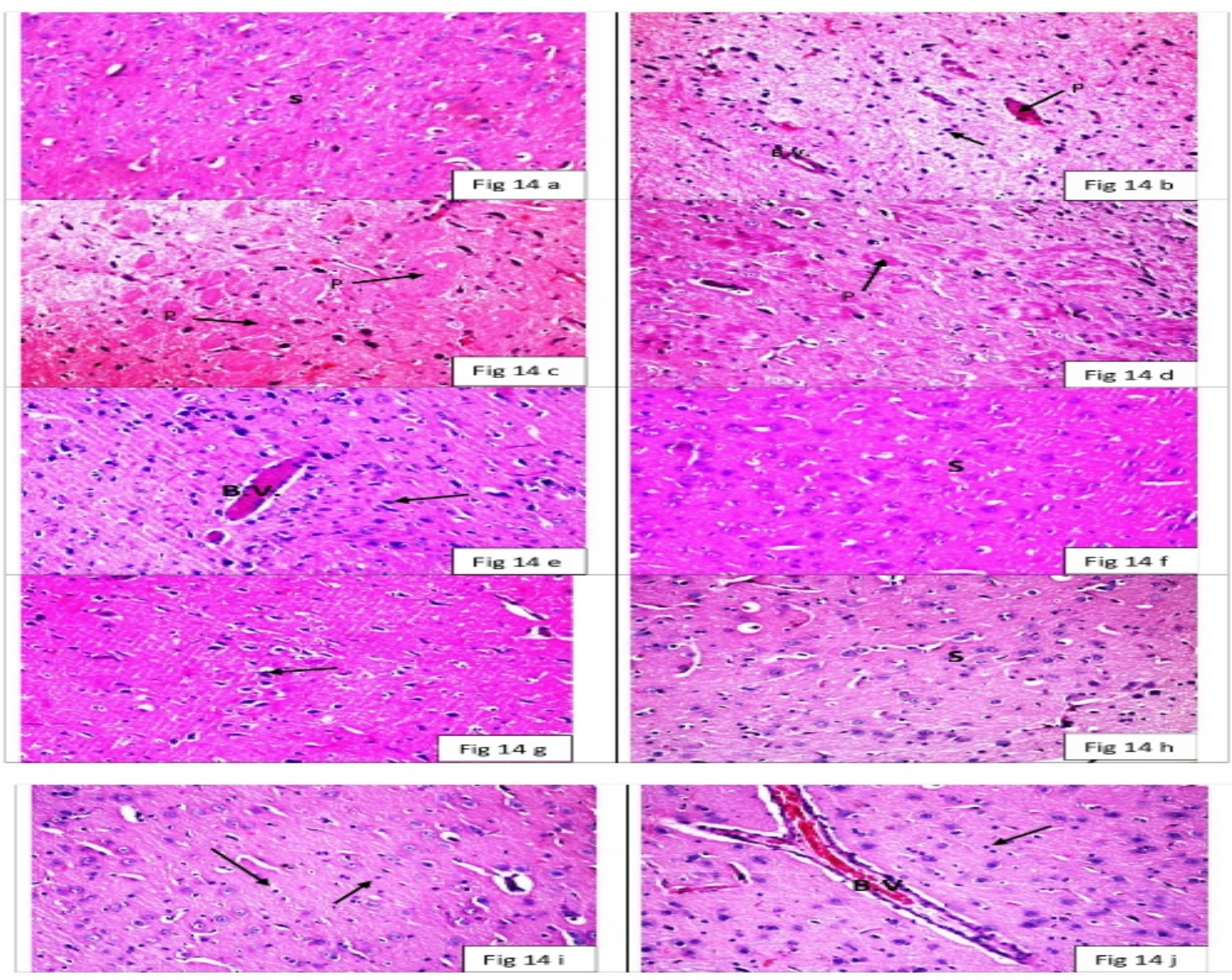

Figure 14: Representative Photomicrographs Of Striatum (S) From Brain Sections Showing: A- Normal Histological Structure In Nf Control Rats (H\&E 40), B- Focal Multiple Eosinophilic Plagues Formation (P), Congestion In Blood Vessels (B.V.) And Nuclear Pyknosis And Degeneration (Arrow) In Nf $\mathrm{Mncl}_{2}$ Intoxicated Rats (H\&E 40), CMultiple Focal Eosinophilic Plagues (P) Formation ]In Nf $\mathrm{Mncl}_{2}+\mathrm{Co}$ Q10 Treated Rats (H\&E 40), D- Multiple Focal

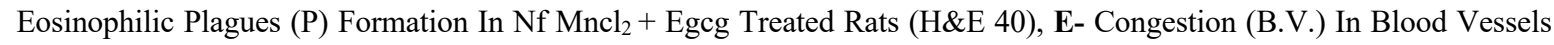
With Nuclear Pyknosis And Degeneration (Arrow) In Nf $\mathrm{Mncl}_{2}+$ Combination Treated Rats (H\&E 40), F- Normal Histological Structure In Low Protein Diet - Fed Control Rats (H\&E 40), G- Nuclear Pyknosis And Degeneration (Arrow) In Low Protein Diet - Fed $\mathrm{Mncl}_{2}$ Intoxicated Rats (H\&E 40), H- Normal Histological Structure In Low Protein Diet - Fed $\mathrm{Mncl}_{2}+\mathrm{Co} \mathrm{Q} 10$ Treated Rats (H\&E 40), I- Few Diffuse Gliosis (Arrow) In Between The Intact Neurons In Low Protein Diet - Fed $\mathrm{Mncl}_{2}+$ Egcg Treated Rats (H\&E 40), J- Congestion (B.V.) In Blood Vessels With Diffuse Gliosis (Arrow) In

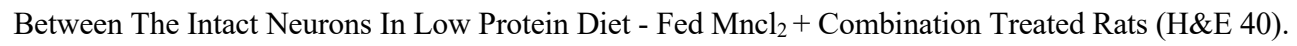

cellular energy metabolism and/or have antioxidative properties with low side effects take interesting attention as a protective policy ${ }^{41}$.

\section{DISCUSSION}

Exposure to environmental toxins is considered a major risk factor for PD. Mn Exposure may cause neurodegeneration due to mitochondrial dysfunction, oxidative stress, and $\alpha$-Synuclein ( $\alpha$-syn) aggregation result in a case called Manganism with a parkinsonian-like symptoms ${ }^{40}$.

Mitochondrial dysfunction and oxidative stress are the main causative factors for neurodegeneration; opens new perceptions of research on antioxidant agents as a possible preventive and therapeutic strategy for $\mathrm{PD}^{26}$. $\mathrm{PD}$ progression usually takes a long time before symptoms start so diets modification and medicinal plants that control
Therefore, the current study was undertaken to investigate the effect of Coenzyme Q10 (Co Q 10) and/or Epigallocatechin-3-gallate (EGCG), as a new natural protective strategy because of its effect on mitochondrial function and its antioxidant, antiinflammatory, and neuroprotective effects, on Parkinson-like symptoms induced by $\mathrm{Mn}$, and also investigated the influence of low protein diet, as an example of nutrition modification, on the effect of Coenzyme Q10 and/or EGCG on Parkinson-like symptoms induced by $\mathrm{Mn}$.

The brain is the primary target organ for chronic exposure to $\mathrm{Mn}$, as it alters behavior, motor function, 
and brain neurotransmitters, Dopamine (DA), Serotonin (5-HT), and Norepinephrine (NE); the vital neurotransmitters to brain functioning and are the key managers of motor function ${ }^{42}$.

Consequently, in this current work, four behavioral tasks evaluating motor and non-motor functions were carried out: grid, swimming, open field, and Y-maze tests, together with evaluation of monoamines DA, NE, 5-HT in the striatum as well as the histological examination of different regions of the brain. The results showed that daily administration of $\mathrm{Mn}$ in a dose of $10 \mathrm{mg} / \mathrm{kg}$ for 5 weeks I.P. to normally fed or low protein diet-fed rats caused: A significant increase in the duration of catalepsy (movement latency in the grid test), latency time (decision making) and swimming time (muscular strength and neuromuscular coordination) together with a decrease in the direction score (vigilance, attention and learning ability) in the swimming test as well as significant impairment in locomotor activity, excitability, emotionality and exploratory behavior in the open field test (through prolongation of latency time and decrease of ambulation, rearing, and grooming frequencies) and significant decline in cognitive functions of exposed rats manifested as a significant decrease in the $\%$ of spontaneous alternation in the Y-maze test in Mntreated rats. However, Mn did not exert a significant effect on rearing frequency and \% of spontaneous alteration in low protein diet-fed rats. This indicated that excessive exposure to $\mathrm{Mn}$ could lead to the development of bradykinesia and rigidity, impaired neuromuscular coordination, decrease excitability and induce anxiety (emotional disturbances) as well as depressive-like behavior in rats.

These results are in agreement with several studies ${ }^{26,43,44}$ reported that $\mathrm{MnCl}_{2}$ toxicity in rats resulted in a cataleptic behavior in the bar and grid tests, reflecting the development of akinesia and rigidity, which might be due to suppressing $\mathrm{D}_{2}$ receptors in the striatum ${ }^{45}$.

This finding is further confirmed by current biochemical results (depletion of DA and NE in the striatum), imitating defects in the dopaminergic neurons after $\mathrm{Mn}$ exposure and histopathological results, reporting nuclear pyknosis and degeneration in the hippocampus, $\mathrm{CC}$, and striatum, a result which in agreement with the previous studies ${ }^{26,43,44,46-50}$.

The impairment of motor function may be partially attributed to degeneration of dopaminergic neurons in the substantia nigra (SN) and striatum and to the related striatal DA level which plays an important role in locomotor activity, learning, and emotion $^{40}$. The reduction of both NE and 5-HT striatal levels may be related to non-motor disabilities ${ }^{51,52}$.
In addition, movement alteration is concomitant with increased oxidative stress in the striatum ${ }^{53}$, which is the cornerstone of Manganism ${ }^{54}$. This study evoked that $\mathrm{Mn}$ increased lipid peroxidation (malondialdehyde (MDA)) level and reduced superoxide dismutase (SOD) and total antioxidant capacity (TAC) in striatal tissue in normally fed or low protein diet-fed rats imitating a condition of oxidative stress. These results are in coherence with a previous study that $\mathrm{Mn}$-intoxicated rats showed increasing lipid peroxides ${ }^{55}$.

It was obvious that Manganism occurs due to oxidative stress and mitochondrial dysfunction ${ }^{56}$. Oxidative stress causes deficiency of the function of mitochondria by destroying the inner membrane and induction of apoptosis: impairing oxidative phosphorylation and ATP production and increasing the generation of $\operatorname{ROS}^{57-59}$. These findings seem to be parallel with the current study revealed suppression of Complex-I content, SOD, and TAC and increased MDA level in striatal tissue, confirming the role of oxidative stress and mitochondrial impairment in Manganism, in consistence with the previous reports ${ }^{60-62,55,44}$.

It was also verified that $\mathrm{Mn}$ toxicity is complemented with inflammation and release of inflammatory mediators and activation of microglia and/or astrocytes, as evidenced by increasing proinflammatory mediators ${ }^{63}$. In the current study, Mn exposure increased the striatal proinflammatory cytokines Tumor necrosis factor-alpha (TNF- $\alpha$ ) and cyclooxygenase II enzyme (COX-II) following the previous studies ${ }^{64,65,44}$.

A previous study recommends that alterations of BDNF signaling in different brain regions may produce the depressive-like behavior induced by the 6-OHDA-caused dopaminergic neuronal loss in rats. This data is consistent with the current study which evoked a decrease in BDNF level in the striatum after Mn exposure in both normal and low protein diet-fed rats, explaining the non-motor deficit and neurodegeneration ${ }^{66}$.

Examination of diet in PD has paid less attention. However, several dietary habits have been shown to alter the risk of PD. So, we reviewed the link between a low protein diet and PD risk.

By comparing the two diet regimens on Mntreated rats, it was found that $\mathrm{Mn}$ in low protein dietfed rats lead to a marked decrease in latency in the grid, swimming, and open field, and swimming time. While it showed a significant increase in swimming score, ambulation, rearing, grooming frequencies in open field test, and \% of spontaneous alteration in $\mathrm{Y}$ maze when compared to its corresponding group of normally fed rats. Also, it significantly increased monoamine content in the striatum except for DA as well as Complex-I content in the striatum. While it 
decreased MDA and anti-inflammatory biomarkers levels in the striatum. But it has a non-significantly effect on SOD, TAC, BDNF, and DA content in the striatum when compared to its corresponding group under a normal diet. Indicating that a low protein diet attenuates most of the toxic effect of Mn on rats.

In consistence with the current study, a previous study showed that simultaneous low protein $(10 \%$ casein) diet with $\mathrm{Mn}$ intoxication ( $3 \mathrm{mg} / \mathrm{ml}$ drinking water) affect levels of DA, NE, and 5-HT in the brain revealed that $\mathrm{Mn}$ in low protein diet group significantly increased the DA and NE levels and reduced 5-HT level, indicating that diet rebuilding (low protein diet) attenuated Mn-toxicity ${ }^{67}$. Another study tested the adjusting of the dietary Protein to Carbohydrate (P: C) ratio to alter the beginning of PD like phenotype in Drosophila parkin null flies, found that parkin- flies served with a 1:16 P: C diet improved lifespan than those served with 1:2 P: C diet. In addition, flies fed the 1:16 P: C diet enhanced catalepsy test and locomotor activity. While males served with the 1:16 P: C diet decreased ROS and SOD activity ${ }^{68}$.

A third study suggested that increase protein in the diet may result in an unevenness between the generation of ROS and the power of the antioxidant defense system in the alimentary canal of mice ${ }^{69}$ and increase oxidative stress and mitochondrial dysfunction in the kidney and aorta of Zucker obese rats $^{70,71}$. It was reported that urinary Mn excretion was inversely proportional to serum albumin that decreases its toxicity ${ }^{72}$.

In the investigated functional alterations by $\mathrm{Mn}$ toxicity in NF and low protein diet-fed rats such as behavioral alteration and neurotransmitter alteration, several possible common mechanisms were evaluated. Oxidative stress and mitochondrial dysfunction may be such mechanisms, as $\mathrm{Mn}$ is known to induce the generation of ROS in living tissue and impair mitochondrial function and respiratory chain reaction, as well as the neuroinflammation mechanism, has also been stated for Manganism. Co Q10 and EGCG, as antioxidant, anti-inflammatory, and neuroprotective agents, have been tested in this study for some counter effects on the behavioral alterations, neurotransmitters, and biochemical parameters induced by Mn.

Counteracting of catalepsy induced by Mn via significantly reducing the duration of catalepsy (moving latency grid), restoration of impaired neuromuscular coordination, attention, vigilance, and decline in the locomotor activity together with counteracting of anxiety and depressive-like behaviors induced by $\mathrm{Mn}$ via significantly reducing latency and swimming times while increasing direction score in the swimming test as well as decreasing latency time while increased ambulation, rearing and grooming frequencies in open field test respectively, as well as improvement of the spatial working memory by attenuating the decline in cognitive functions in the $\mathrm{Y}$-maze test (increasing the $\%$ of spontaneous alternation), by CoQ10, EGCG and their combination in normally fed or low protein diet-fed rats as compared to $\mathrm{Mn}$-treated rats. These results for Co Q10 or EGCG are in harmony with the previous studies ${ }^{73-76 ; 43,77-79}$. A study showed that EGCG or its combination with caffeine in Mnexposed rats contrasted the catalepsy observed after $\mathrm{Mn}$ in grid and bar tests ${ }^{43}$. Another one revealed that Co Q10 nano-emulsion improved the behavioral activities in forced swimming test in haloperidol challenged rats by reducing nigrostriatal dopamine depletion $^{75}$.

EGCG has been shown neuroprotective effects in various PD models ${ }^{80}$. A previous study showed a slight improvement in motor functions after 14-day pretreatment with EGCG in 6-OHDA-treated rats ${ }^{81}$. On the other hand, two reviews on clinical trials were exhibited that CoQ10 did not improve motor functions in NDD patients ${ }^{12,82}$.

While in low protein diet-fed rats, Co-enzyme Q10, EGCG, or their combination significantly decreased latency in swimming and open field and swimming time. While they did not show any significant alteration in swimming score. But EGCG by itself or its combination with Co Q10 increased ambulation frequency, while the combination of both Co Q10 and EGCG increased rearing frequency, and Co Q10 by itself or its combination with EGCG increased grooming frequencies in the open field test.

This result was closely related to restoration of the depleted monoamines (DA, NE, and 5-HT) contents in the striatum, a result which is confirmed by attenuation of neuronal degeneration in the hippocampus, striatum, and $\mathrm{CC}$ achieved by administration of Co Q10, EGCG, or their combination to normally fed or low protein diet - fed Mn-exposed rats, that in line with the previous studies $^{83,84 ; 62,77-79,85,86}$.

EGCG could restore the motor function deficits induced by Mn by restoring the depleted striatal DA by protecting dopaminergic neurons in the $\mathrm{SN}$ and striatum against degeneration as showed by histopathological results which are following the studies $^{87,88}$. Moreover, EGCG reversibly inhibits Monoamine Oxidase B(MAO-B) which oxidizes DA and catechol-O-methyl transferase (COMT) ${ }^{89}$ and has strong anti-inflammatory and anti-apoptosis effects $^{90}$.

The neuroprotective effect showed by Co Q10 and EGCG on Mn-treated rats as antioxidant agents and improving mitochondrial respiratory chain reaction by restoring the inhibited complex-I is consistent with the previous studies of ${ }^{91,73,84,75 ; 62}$. A 
previous study demonstrated that Co Q10 prevents the apoptosis caused by mitochondria as it resulted in the restitution of the depleted striatal complex-I, ATP levels, and increased the antiapoptotic protein Bcl$2^{73}$.

Besides the antioxidative effects, Co Q10 and EGCG have an anti-inflammatory response. The current study showed that Co Q10, EGCG, and their combination reduced the elevated TNF alpha and COX-II. The results of EGCG are parallel to the previous studies ${ }^{77,79}$. While up to our knowledge there are no data regarding the effect of Co Q10 on Mn-treated rats. A study has shown that Camellia sinensis (green tea) and its catechins decreased COXII in striatal tissues in 6-OHDA treated animals ${ }^{77}$. And another one has reported that EGCG treatment decreased the concentrations of serum TNF- $\alpha$ and IL-6 in MPTP-treated mice ${ }^{79}$.

Up to our knowledge, most of these previous studies were performed in animal models of Parkinsonism induced by neurotoxins other than Mn because there are no available data about $\mathrm{Mn}$ with $\mathrm{Co}$ Q10 or EGCG or regarding the co-administration of Co Q10 and EGCG to Mn-exposed rats.

Finally, the neuroprotective effect of Co Q10, EGCG, or their combination on Mn neurotoxicity was reinforced by the elevation of the suppressed striatal BDNF level. But, up to our knowledge, there are not any similar data regarding this effect. It was documented that there is a natural glutamate analog in green tea called Gamma-glutamyl-ethyl amide (1theanine) attenuated the down-regulation of BDNF and glial cell line-derived neurotrophic factor (GDNF) induced by rotenone and dieldrin in dopaminergic cell line ${ }^{92}$.

By comparing the two-diet regimen, Co Q10, $\mathrm{EGCG}$, or their combination in low protein diet-fed rats decreased swimming latency. While the combination of Co Q10 and EGCG increased ambulation, rearing, and grooming frequencies in the open field test. In addition, Co Q10 alone increased grooming frequency in open field test and \% of spontaneous alteration in Y-maze test compared to their corresponding groups of normally fed rats and a slight improvement in the histological alteration.

Coenzyme Q10, EGCG, or their combination with $\mathrm{Mn}$ increased monoamine content and oxidative stress biomarkers; SOD and TAC level in the striatum (except EGCG has a non-significant effect on SOD). While they reduced anti-inflammatory biomarkers; TNF- $\alpha$ and COX-II. Although they did not alter MDA content in the striatum. Only EGCG increases BDNF level in the striatum. Co-enzyme Q10 or EGCG alone decreased the level of Complex$\mathrm{I}$ in the striatum when compared to their corresponding group under a normal diet.
Up to the utmost knowledge of the researchers, this is the first study to evaluate the role of Co Q10, EGCG, and their combination on Mn-induced parkinsonian-like symptoms (Manganism) in low protein diet - fed rats. And the results of this study revealed that these treatments would have a more pronounced effect as a low protein diet was found to attenuate Mn-toxicity in rats. The suggested protection of these treatments is based on both their effect and the discovered effect of a low protein diet.

\section{CONCLUSIONS}

In Conclusion, the current work highlights that a low protein diet improved most of the behavioral and biochemical parameters and prevent most of the neuronal degeneration induced by $\mathrm{Mn}$ in different brain regions. Which can be referred to as a reduction in Mn-toxicity. Also, it concluded that administration of Co Q10 and/or EGCG either alone or in combination protects against most neuronal degeneration induced by $\mathrm{Mn}$ in rats on different diet regimens, while their effects were intense in low protein diet-fed rats. Also, the protective effect of EGCG either alone or in combination with Co Q10 was more pronounced than that of Co Q10 alone.

Funding: This research does not receive any fund. Acknowledgments: We wish to acknowledge Dr. Adel Bakeer. Department of Pathology, Faculty of Veterinary Medicine, Cairo University, for his kind help in histological analysis.

Conflicts of Interest: None of the authors have conflicts of interest to declare.

Ethical Statement: The study was conducted in accordance with the Guide for the Care and Use of Laboratory Animals published by the U.S. National Institutes of Health and is approved by the Ethics Committee of Faculty of Pharmacy (Girls), Al-Azhar University, Egypt, Permit Number 203, 2016.

Author Contribution: The authors declare that all data were generated in-house and that no paper mill was used. AA developed the research idea, designed the experiments, supervised the experiment execution, and revised the manuscript; HI shared developing the idea, supervised the experiments execution, supervised the data analysis and revised the manuscript; MM supervised the data analysis and revised the manuscript; AS performed the experiments, collected the data, analyzed the data, performed the graphical and statistical analysis and wrote the manuscript.

\section{List of Abbreviations:}

5-HT; 5-hydroxy tryptamine (serotonin), ATP; Adenosine triphosphate, COX II; Cyclooxygenase II, DA;Dopamine, H \& E; Hematoxyline and Eosin, IL6; Interleukin-6, MDA; Malondialdehyde, Mn; Manganese, MPTP;1-methyl-4-phenyl-1,2,3,6- 
tetrahydropyridine, NE; Norepinephrine, ROS; Reactive oxygen species, SOD; Superoxide dismutase, TAC; Total antioxidant capacity, TNF- $\alpha$; Tumor necrosis factor alpha, UPS; ubiquitinproteasome system,WPI; Whey protein isolate, $\alpha$ Syn; $\alpha$-Synuclein.

\section{REFERENCES}

[1] Wynford-Thomas R, Robertson N. The role of skin biopsy in differentiating idiopathic Parkinson's disease from other types of parkinsonism. Journal of Neurology. 2015;262(12):2793-2795.

[2] Amro MS, Teoh SL, Norzana AG, Srijit D. The potential role of herbal products in the treatment of Parkinson's disease. $\mathrm{La}$ Clinica Terapeutica.2018; 169(1): e23-e33. DOI: http://doi.org/10.7417/CT.2018.2050.

[3] Büeler H. Impaired mitochondrial dynamics and function in the pathogenesis of Parkinson's disease. Experimental neurology.2009; 218(2): 235-246.

DOI: https://doi.org/10.1016/j.expneurol.2009.03.006.

[4] $\mathrm{Hu} \mathrm{Q}$, Wang G. Mitochondrial dysfunction in Parkinson's disease. Transl Neurodegener.2016; 5:14. DOI: https://doi.org/10.1186/s40035-0160060-6

[5] Sveinbjornsdottir S. The clinical symptoms of Parkinson's disease. Journal of neurochemistry.2016; 139: 318-324. DOI: https://doi.org/10.1111/jnc.13691

[6] Gubellini P, Kachidian P. Animal models of Parkinson's disease: An updated overview. Rev Neurol (Paris).2015; 171(11):750-761. DOI: https://doi.org/10.1016/j.neurol.2015.07.011

[7] Cannon JR, Greenamyre JT. The role of environmental exposures in neurodegeneration and neurodegenerative diseases. Toxicological Sciences.2011; 124(2): 225-250. DOI: https://doi.org/10.1093/toxsci/kfr239

[8] Doty RL. Olfactory dysfunction in Parkinson's disease. Nat Rev Neurol. 2012; 8: 329-339. DOI: https://doi.org/10.1038/nrneurol.2012.80.

[9] Erikson KM, Syversen T, Aschner JL, Aschner M. Interactions between excessive manganese exposures and dietary iron-deficiency in neurodegeneration. Environ. Toxicol. Pharmacol.2005; 19: 415-421. DOI: https://doi.org/10.1016/j.etap.2004.12.053.

[10] O’Neal SL, Zheng W. Manganese toxicity upon overexposure: a decade in review. Current environmental health reports.2015; 2(3):315-328. DOI: http://dx.doi.org/10.1007\%2Fs40572-0150056-x.
[11] Krebs N, Langkammer C, Goessler W, Ropele S, Fazekas F, Yen K. Assessment of trace elements in the human brain using inductively coupled plasma mass spectrometry. J Trace Elem Med Biol.2014; 28(1): $1-7 . \quad$ DOI: https://doi.org/10.1016/j.jtemb.2013.09.006

[12] Liu J, Wang LN. Mitochondrial enhancement for neurodegenerative movement disorders: a systematic review of trials involving creatine, coenzyme Q10, idebenone, and mitoquinone. CNS Drugs. 2014; 28:63-68. DOI: https://doi.org/10.1007/s40263-013-0124-4.

[13] Peres TV, Parmalee NL, Martinez-Finley EJ, Aschner M. Untangling the manganese- $\alpha$ synuclein web. Frontiers in neuroscience.2016; 10: 364. DOI: https://doi.org/10.3389/fnins.2016.00364.

[14] Alamy M, Bengelloun WA. Malnutrition and brain development: an analysis of the effects of inadequate diet during different stages of life in rat. Neurosci Biobehav Rev.2012; 36: 1463-1480. DOI:

https://doi.org/10.1016/j.neubiorev.2012.03.009.

[15] Sääksjärvi K, Knekt P, Lundqvist A, Männistö S, Heliövaara M, Rissanen H, Järvinen R. A cohort study on diet and the risk of Parkinson's disease: the role of food groups and diet quality. Br. J. Nutr.2013; 109:329-337. DOI: https://doi.org/10.1017/S000711451200095 $\underline{5}$.

[16] Sanoobar M, Eghtesadi S, Azimi A, Khalil M, Khodadadi B, Jazayeri S, Gohari MR, Aryaeian N. Coenzyme Q10 supplementation ameliorates inflammatory markers in patients with multiple sclerosis: a double blind, placebo, controlled randomized clinical trial. Nutr Neurosci. 2015; 18:169-176.

DOI:https://doi.org/10.1179/1476830513Y.00000 $\underline{00106 .}$

[17] Alam MA, Rahman MM. Mitochondrial dysfunction in obesity: potential benefit and mechanism of Co-enzyme Q10 supplementation in metabolic syndrome. J Diabetes Metab Disord. 2014;13: 60. DOI: https://doi.org/10.1186/22516581-13-60.

[18] Stough C, Nankivell M, Camfield DA, Perry NL, Pipingas A, Macpherson H, wesnes K, Ou R, Hare D, de Haan J, Head G, Lansjoen P, Langsjoen A, Tan B, Pase MP, King R, Rowsell R, Zwalf O, Rathner Y, Cooke M, Head G. CoQ10 and Cognition a review and study protocol for a 90-day randomized controlled trial investigating the cognitive effects of Ubiquinol in the healthy 
elderly. Frontiers in aging neuroscience. 2019; 11:103.

DOI:

https://doi.org/10.3389/fnagi.2019.00103.

[19] Cascella M, Bimonte S, Muzio MR, Schiavone V, Cuomo A. The efficacy of Epigallocatechin-3gallate (green tea) in the treatment of Alzheimer's disease: an overview of pre-clinical studies and translational perspectives in clinical practice. Infectious agents and cancer.2017; 12(1):36.

DOI: https://doi.org/10.1186/s13027-017-0145-6.

[20] Lee JW, Lee YK, Ban JO, Ha TY, Yun YP, Han $\mathrm{SB}$, Oh KW, Hong JT. Green tea (-)epigallocatechin-3-gallate inhibits $\beta$-amyloidinduced cognitive dysfunction through modification of secretase activity via inhibition of ERK and NF- $\kappa \mathrm{B}$ pathways in mice. Journal of Nutrition.2009; 139(10):1987-1993. DOI: https://doi.org/10.3945/jn.109.109785.

[21] Zhang B, Wang B, Cao S, Wang Y. Epigallocatechin-3- gallate (EGCG) attenuates traumatic brain injury by inhibition of edema formation and oxidative stress. The Korean Journal of Physiology \& Pharmacology. 201519 (6):491497.

DOI: https://doi.org/10.4196/kjpp.2015.19.6.491.

[22] Ortiz-Lopez L, M' arquez-Valadez B, G ' omez-S ' anchez A. Green tea compound epigallocatechin-3-gallate (EGCG) increases neuronal survival in adult hippocampal neurogenesis in vivo and in vitro. Neuroscience.2016; 322: 208-220. DOI:

https://doi.org/10.1016/j.neuroscience.2016.02.04 $\underline{0}$.

[23] Xicota L, Rodr' 1guez-Morato J, Dierssen M, De La ' Torre R. Potential role of (-)-epigallocatechin-3gallate (EGCG) in the secondary prevention of alzheimer disease. Current Drug Targets.2017; 16:174: $195 . \quad$ DOI: http://dx.doi.org/10.2174/13894501166661508251 13655.

[24] Scholey A, Downey LA, Ciorciari J, Pipingas A, Nolidin K, Finn M, Wines M, Catchlove S, Terrens A, Barlow E, Gordon L, Stough C. Acute neurocognitive effects of epigallocatechin gallate (EGCG). Appetite. 2012; 58 (2):767-770. DOI: https://doi.org/10.1016/j.appet.2011.11.016.

[25] Ali AA, Ahmed HI, Khalil MG, Alwakeel AI, Elfotuh KA. Comparative Study on the Influence of Epigallocatechin-3-gallate and/or Coenzyme Q10 against Alzheimer's disease Induced by Aluminium in Normally-Fed and Protein Malnourished Rats. $J$ Alzheimers Dis
Parkinsonism.2016; 6(240):100240. DOI: http://dx.doi.org/10.4172/2161-0460.1000240.

[26] Bouabid S, Delaville C, De Deurwaerdère P, Lakhdar-ghazal N, Benazzouz A. Manganeseinduced atypical parkinsonism is associated with altered basal ganglia activity and changes in tissue levels of monoamines in the rat. PLoS One.2014; 9 (6):

98952. DOI:https://doi.org/10.1371/journal.pone.0098952

[27] Xie T, Wang WP, Mao ZF, Qu ZZ, Luan SQ, Jia LJ, Kan MC. Effects of epigallocatechin-3-gallate on pentylenetetrazole-induced kindling, cognitive impairment and oxidative stress in rats. Neuroscience Letters. 2012; 516(2): 237-241. DOI: https://doi.org/10.1016/j.neulet.2012.04.001.

[28] Sanberg PR, Bunsey MD, Giordano M, Norman AB. The catalepsy test: its ups and downs. Behav. Neurosci. 1988; 102(5):748-759. DOI: https://doi.org/10.1037/0735-7044.102.5.748.

[29] Ali AA, Hamed MR, El-Sayed M. Effect of protein Malnutrition on postnatal Neurobehavioural Response to Drugs, M. Sc. Thesis, Pharmacology, Faculty of Pharmacy, Cairo, University. 1992: 159160.

[30] Genaro G, Schmidek WR. Exploratory activity of rats in three Different environments. Ethology.2000; 106:849-859. DOI: https://doi.org/10.1046/j.1439-0310.2000.00605.x.

[31] Sedelis M, Schwarting RK, Huston JP. Behavioral phenotyping of the MPTP mouse model of Parkinson's disease. Behav. Brain Res.2001; 125:109-125. DOI: https://doi.org/10.1016/S01664328(01)00309-6.

[32] Cunha JM, Masur J. Evaluation of psychotropic drugs with a modified open field test. Pharmacology. 1987; 16(5):259-267. DOI: https://doi.org/10.1159/000136777.

[33] Volosin M, Cancela L, Molina V. Influence of adrenocorticotrophic hormone on the behaviour in the swim test of rats treated chronically with desipramine. J Pharm Pharmacol.1988; 40(1):7476. DOI: $\quad$ https://doi.org/10.1111/j.20427158.1988.tb05160.x.

[34] Capitelli C, Sereniki A, Lima MM, Reksidler AB, Tufik S, Vital MA. Melatonin attenuates tyrosine hydroxylase loss and hypolocomotion in MPTPlesioned rats. Eur. J. Pharmacol.2008; 594:101108.

DOI: https://doi.org/10.1016/j.ejphar.2008.07.022.

[35] Van Wimersma Greidanus TB, Maigret C, Torn M, Ronner E, Van der Kracht S, Van der Wee NJ, 
Versteeg DH. Dopamine D-1 and D-2 receptor agonists and antagonists and neuropeptide-induced excessive grooming. Eur. J. Pharmacol.1989; 173:227-231. DOI: https://doi.org/10.1016/00142999(89)90527-X

[36] Sarter M, Bodewitz G, Stephens DN. Attenuation of scopolamine-induced impairment of spontaneous alteration behaviour by antagonist but not inverse agonist and agonist beta-carbolines. Psychopharmacology (Berl).1988; 94(4):491-495. DOI:https://doi.org/10.1007/BF00212843.

[37] Teixeira MD, Souza CM, Menezes AP, Carmo MR, Fonteles AA, Gurgel JP, Lima FA, Viana GS, Andrade GM. Catechin attenuates behavioral neurotoxicity induced by 6-OHDA in rats. Pharmacol. Biochem. Behav.2013; 110:1-7. DOI:https://doi.org/10.1016/j.pbb.2013.05.012.

[38] Bancroft JD, Gamble M. Theory and Practice of Histological Techniques. 6 th Ed., Churchill Livingstone, Elsevier.2008, New York, London, San Francisco, Tokyo.

[39] Jafari S, Etminan M, Aminzadeh F, Samii A. Head injury and risk of Parkinson disease: A systematic review and metaanalysis. Mov Disord. 2013; 28:1222-1229.

DOI: https://doi.org/10.1002/mds.25458.

[40] Peres TV, Schettinger MRC, Chen P, Carvalho F, Avila DS, Bowman AB, Aschner M. Manganeseinduced neurotoxicity: a review of its behavioral consequences and neuroprotective strategies. $B M C$ Pharmacol Toxicol.2016; 17: 57-77. DOI: https://doi.org/10.1186/s40360-016-0099-0.

[41] Sarrafchi A, Bahmani M, Shirzad H, RafieianKopaei M. Oxidative stress and Parkinson's disease: new hopes in treatment with herbal antioxidants. Current pharmaceutical design.2016; 22(2):238-246.

DOI: https://doi.org/10.2174/138161282266615111215 1653.

[42] Garcia SJ, Gellein K, Syversen T, Aschner M. A manganese-enhanced diet alters brain metals and transporters in the developing rat. Toxicol. Sci. 2006; 92(2):516-525. https://doi.org/10.1093/toxsci/kfl017.

[43] Ali AA, Ahmed HI, Abdelaty A. Modulatory effects of bisphenol A, caffeine, epigallocatechin3-gallate and their combinations against parkinsonism in rats. $J$ Alzheimers Dis Parkinsonism.2017; 7 (5): $53 . \quad$ DOI: http://doi.org/10.4172/2161-0460-C1-031. (abstract in conference).

[44] Nadeem RI, Ahmed HI, El-Sayeh BM. Protective effect of vinpocetine against neurotoxicity of manganese in adult male rats. NaunynSchmiedeberg's archives of pharmacology.2018; 391(7):729-742. DOI: https://doi.org/10.1007/s00210-018-1498-0.

[45] Kobayashi H, Uchida M, Sato I, Suzuki T, Hossain MM, Suzuki K. Neurotoxicity and Brain Regional Distribution of Manganese in Mice. Toxicol Toxin Rev. 2003; 22(4):679-689. DOI: https://doi.org/10.1081/TXR-120026921.

[46] Cordova F, Jr. Aguiar A, Peres T, Lopes M, Gonçalves F, Pedro D, Lopes S, Pilati C, Prediger RS, Farina M, Erikson KM, Aschner M, leal RB. Manganese-exposed developing rats display motor deficits and striatal oxidative stress that are reversed by Trolox. Arch Toxicol. 2013; 87(7):1231-1244.

DOI:

https://doi.org/10.1007/s00204-013-1017-5.

[47] Beaudin SA, Strupp BJ, Lasley L, Smith DR. Oral Methylphenidate Alleviates the Fine Motor Dysfunction Caused by Chronic Postnatal Manganese Exposure in Adult Rats. Toxicol Sci. 2015; 144(2): 318-327. DOI: https://doi.org/10.1093/toxsci/kfv007.

[48] Su C, Chen K, Zou Y, Shen Y, Xia B, Liang G, Lv Y, Wang F, Huang D, Yang X. Chronic Exposure to Manganese Sulfate Leads to Adverse DoseDependent Effects on the Neurobehavioral Ability of Rats. Environ Toxicol.2016; 31:1571-1579. DOI: https://doi.org/10.1002/tox.22161.

[49] Bahar E, Kim JY, Yoon H. Quercetin attenuates manganese-induced neuroinflammation by alleviating oxidative stress through regulation of apoptosis, iNOS/NF- $\mathrm{B}$ and $\mathrm{HO}-1 / \mathrm{Nrf} 2$ pathways. International journal of molecular sciences. 2017; 18(9):1989. DOI: https://doi.org/10.3390/ijms18091989.

[50] Ali MF, Taha M. Pathological and hematological studies on the effect of curcumin on manganese chloride-induced neurotoxicity in rats. Comparative Clinical Pathology. 2019; 28(1):69-82. DOI: https://doi.org/10.1007/s00580-018-02888-6.

[51] Temel Y, Boothman LJ, Blokland A, Magill PJ, Steinbusch HWM. Inhibition of 5-HT neuron activity and induction of depressive-like behavior by high-frequency stimulation of the subthalamic nucleus. Proceedings of the National Academy of Sciences. 2007; 104:17087-17092. DOI: https://doi.org/10.1073/pnas.0704144104.

[52] Delaville C, Chetrit J, Abdallah K, Morin S, Cardoit L, De Deurwaerdere P, Benazzouz A. Emerging dysfunctions consequent to combined monoaminergic depletions in parkinsonism. 
Neurobiology of Disease. 2012; 45: 763-773. DOI: https://doi.org/10.1016/j.nbd.2011.10.023.

[53] De Oliveira MR, de Bittencourt Pasquali MA, Silvestrin RB, Mello EST, Moreira JC. Vitamin A supplementation induces a prooxidative state in the striatum and impairs locomotory and exploratory activity of adult rats. Brain Res. 2007; 1169:112119.

DOI: https://doi.org/10.1016/i.brainres.2007.07.008.

[54] Liu Y, Barber DS, Zhang P, Liu B. Complex II of the mitochondrial respiratory chain is the key mediator of divalent manganese-induced hydrogen peroxide production in microglia. Toxicol Sci.2013; $\quad$ 132(2):298-306. DOI: https://doi.org/10.1093/toxsci/kfs344.

[55] Apaydin M, Erbas O, Taskiran D. Protection by Edaravone, a radical scavenger, against manganese-induced neurotoxicity in rats. $J$ Biochem Mol Toxicol. 2016; 30(5): 217-223. DOI: https://doi.org/10.1002/jbt.21780.

[56] Majid T, Ali YO, Venkitaramani DV, Jang MK, Lu $\mathrm{HC}$, Pautler RG. In vivo axonal transport deficits in a mouse model of fronto-temporal dementia. Neuroimage Clin. 2014; 4: 711-717. DOI: https://doi.org/10.1016/j.nicl.2014.02.005.

[57] Zhang S, Fu J, Zhou Z. In vitro effect of manganese chloride exposure on reactive oxygen species generation and respiratory chain complexes activities of mitochondria isolated from rat brain. Toxicol in Vitro. 2004; 18(1):71-77. DOI: https://doi.org/10.1016/j.tiv.2003.09.002.

[58] Avila DS, Colle D, Gubert P, Palma AS, Puntel G, Manarin F, Noremberg S, Nascimento PC, Aschner M, Rocha JBT, Soares FAA. A Possible Neuroprotective Action of a Vinylic Telluride against Mn-Induced Neurotoxicity. Toxicological Sciences. 2010; 115:194-201. DOI: https://doi.org/10.1093/toxsci/kfq036.

[59] Milatovic D, Yin Z, Gupta RC, Sidoryk M, Albrecht J, Aschner JL, Aschner M. Manganese induces oxidative impairment in cultured rat astrocytes. Toxicol Sci. 2007: 98(1):198-205. DOI: https://doi.org/10.1093/toxsci/kfm095.

[60] Chtourou Y, Fetoui H, Garoui el M, Boudawara T, Zeghal N. Improvement of cerebellum redox states and cholinergic functions contribute to the beneficial effects of silymarin against manganese induced neurotoxicity. Neurochem Res. 2012; 37(3):469-479.

https://doi.org/10.1007/s11064-011-0632-X.

[61] Szpetnar M, Luchowska-Kocot D, BoguszewskaCzubara A, Kurzepa J. The influence of manganese and glutamine intake on antioxidants and neurotransmitter amino acids levels in rats' brain. Neurochem Res. 2016; 41(8):2129-2139. DOI: https://doi.org/10.1007/s11064-016-1928-7.

[62] Ali AA, Ahmed HI, Abdelaty A. The Possible Interaction between Bisphenol a, Caffeine and Epigallocatechin-3-Gallate on Neurotoxicity Induced by Manganese in Rats. 19th International Conference on Environmental Pollution and Pollution Control, London United Kingdom. 2017; Volume 19 (1) Part IX.

[63] Milatovic D, Zaja-Milatovic S, Gupta RC, Yu Y, Aschner M. Oxidative damage and neurodegeneration in manganese-induced neurotoxicity. Toxicol Appl Pharmacol. 2009; 240(2):219-225.

DOI: https://doi.org/10.1016/j.taap.2009.07.004.

[64] Liu G, Zhang C, Yin J, Li X, Cheng F, Li Y, Yang $\mathrm{H}$, Ueda K, Chan P, Yu S. alpha-Synuclein is differentially expressed in mitochondria from different rat brain regions and dose-dependently down-regulates complex I activity. Neurosci. Lett.2009; $\quad 454: 187-192 . \quad$ DOI: https://doi.org/10.1016/j.neulet.2009.02.056.

[65] Zhao F, Cai T, Liu M, Zheng G, Luo W, Chen J. Manganese induces dopaminergic neurodegeneration via microglial activation in a rat model of manganism. Toxicol Sci. 2009; 107(1):156-164.

DOI: https://doi.org/10.1093/toxsci/kfn213.

[66] Berghauzen-Maciejewska K, Wardas J, Kosmowska B, Głowacka U, Kuter K, Ossowska $\mathrm{K}$. Alterations of BDNF and trkB mRNA expression in the 6-hydroxydopamine-induced model of preclinical stages of Parkinson's disease: an influence of chronic pramipexole in rats. PloS one. $\quad 2015$; 10(3):0117698. DOI: https://doi.org/10.1371/journal.pone.0117698.

[67] Ali MM, Murthy RC, Mandal SK, Chandra SV. Effect of low protein diet on manganese neurotoxicity: III. Brain neurotransmitter levels. Neurobehavioral toxicology and teratology. 1985; 7(5):427-443.

[68] Bajracharya R, Ballard JWO. Low protein to carbohydrate ratio diet delays onset of Parkinsonism like phenotype in Drosophila melanogaster parkin null mutants. Mechanisms of ageing and development. 2016; 160:19-27. DOI: https://doi.org/10.1016/j.mad.2016.10.003.

[69] Gu C, Shi Y, Le G. Effect of dietary protein level and origin on the redox status in the digestive tract of mice. Int. J. Mol. Sci.2008; 9: 464-475. DOI: https://doi.org/10.3390/ijms9040464. 
[70] Camiletti-Moirón D, Aparicio VA, Nebot E, Medina G, Martínez R, Kapravelou G, Andrade A, Porres JM, López-Jurado M, Aranda P. Highprotein diet induces oxidative stress in rat brain: protective action of high-intensity exercise against lipid peroxidation. Nutr. Hosp.2014; 31:866-874. DOI: https://doi.org/10.3305/nh.2015.31.2.8182.

[71] Namikoshi T, Tomita N, Satoh M, Haruna Y, Kobayashi S, Komai N, Sasaki T, Kashihara N. Olmesartan ameliorates renovascular injury and oxidative stress in Zucker obese rats enhanced by dietary protein. Am. J. Hypertens. 2007; 20:10851091.

DOI: https://doi.org/10.1016/i.amjhyper.2007.05.007.

[72] Gonzalez-Reimers E, Martinez-Riera A, Santolaria-Fernandez F, Mas-Pascual A, Rodriguez-Moreno F, Galindo-Martin L, BarrosLopez N. Relative and combined effects of ethanol and protein deficiency on zinc, iron, copper, and manganese contents in different organs and urinary and fecal excretion. Alcohol. 1998; 16(1): 7-12. DOI: $\quad$ https://doi.org/10.1016/S07418329(97)00156-0.

[73] Abdin AA, Hamouda HE. Mechanism of the neuroprotective role of coenzyme Q10 with or without L-dopa in rotenone-induced parkinsonism. Neuropharmacology.

2008; 55(8):1340-1346.

DOI: https://doi.org/10.1016/j.neuropharm.2008.08.033.

[74] Yang L, Calingasan NY, Wille EJ, Cormier K, Smith K, Ferrante RJ, Flint Beal M. Combination therapy with coenzyme Q10 and creatine produces additive neuroprotective effects in models of Parkinson's and Huntington's diseases. Journal of neurochemistry. 2009; 109(5):1427-1439. DOI: https://doi.org/10.1111/j.1471-4159.2009.06074.x.

[75] Gupta BK, Kumar S, Kaur H, Ali J, Baboota S. Attenuation of Oxidative Damage by Coenzyme Q10 Loaded Nanoemulsion Through Oral Route for the Management of Parkinson's Disease. Rejuvenation research. 2018; 21(3):232248. DOI: https://doi.org/10.1089/rej.2017.1959.

[76] Attia HN, Maklad YA. Neuroprotective effects of coenzyme Q10 on paraquat-induced Parkinson's disease in experimental animals. Behavioural pharmacology. 2018; 29(1):79-86. DOI: https://doi.org/10.1097/FBP.0000000000000342.

[77] Bitu Pinto N, da Silva Alexandre B, Neves KRT, Silva AH, Leal LKA, Viana GS. Neuroprotective properties of the standardized extract from Camellia sinensis (green tea) and its main bioactive components, epicatechin and epigallocatechin gallate, in the 6-OHDA model of Parkinson's disease. Evidence-Based Complementary and
Alternative Medicine. 2015; 2015:161092. DOI: https://doi.org/10.1155/2015/161092.

[78] Xu Q, Langley M, Kanthasamy AG, Reddy MB. Epigallocatechin gallate has a neurorescue effect in a mouse model of parkinson disease. J. Nutr. 2017; 147:1926-1931.

DOI: https://doi.org/10.3945/jn.117.255034.

[79] Zhou T, Zhu M, Liang Z. (-)-epigallocatechin-3gallate modulates peripheral immunity in the mptpinduced mouse model of parkinson's disease. Mol. Med. Rep.2018;17:4883-4888. DOI: https://doi.org/10.3892/mmr.2018.8470.

[80] Jung UJ, Kim SR. Beneficial effects of flavonoids against parkinson's disease. Journal of medicinal food. 2018; 21(5): 421-432. DOI: https://doi.org/10.1089/jmf.2017.4078.

[81] Leaver KR, Allbutt HN, Creber NJ, Kassiou M, Henderson JM. Oral pre-treatment with epigallocatechin gallate in 6-ohda lesioned rats produces subtle symptomatic relief but not neuroprotection. Brain Res. Bull. 2009; 80:397402.DOI:

https://doi.org/10.1016/j.brainresbull.2009.08.013.

[82] Negida A, Menshawy A, El Ashal G, Elfouly Y, Hani Y, Hegazy Y, Rashad Y. Coenzyme Q10 for patients with Parkinson's disease: a systematic review and meta-analysis. CNS \& Neurological Disorders-Drug Targets (Formerly Current Drug Targets-CNS \& Neurological Disorders). 2016; 15(1): 45-53. DOI: https://doi.org/10.2174/187152731466615082110 $\underline{3306}$.

[83] Cleren C, Yang L, Lorenzo B, Calingasan NY, Schomer A, Sireci A, Wille EJ, Beal MF. Therapeutic effects of coenzyme Q10 (CoQ10) and reduced CoQ10 in the MPTP model of Parkinsonism. Journal of neurochemistry. 2008; 104(6): pp. 1613-1621. DOI: https://doi.org/10.1111/j.1471-4159.2007.05097.x.

[84] Binukumar BK, Gupta N, Sunkaria A, Kandimalla R, Wani WY, Sharma DR, Bal A, Gill KD. Protective efficacy of coenzyme Q10 against DDVP-induced cognitive impairments and neurodegeneration in rats. Neurotoxicity research. 2012; 21(4):345-357.

DOI: https://doi.org/10.1007/s12640-011-9289-0.

[85] Teixeira MD, Souza CM, Menezes AP, Carmo MR, Fonteles AA, Gurgel JP, Lima FA, Viana GS, Andrade GM. Catechin attenuates behavioral neurotoxicity induced by 6-OHDA in rats. Pharmacol. Biochem. Behav. 2013; 110:1-7. DOI: https://doi.org/10.1016/j.pbb.2013.05.012.

[86] Renaud J, Nabavi SF, Daglia M, Nabavi SM, Martinoli MG. Epigallocatechin-3-gallate, a 
promising molecule for Parkinson's disease?. Rejuvenation research. 2015; 18(3):257269. DOI: https://doi.org/10.1089/rej.2014.1639.

[87] Levites Y, Weinreb O, Maor G, Youdim $\mathrm{MBH}$, Mandel S. Green tea polyphenol (-)epigallocatechin-3-gallate prevents N-methyl-4phenyl-1,2,3,6-tetrahydropyridine-induced dopaminergic neurodegeneration. $J$ Neurochem. 2001; 78(5):1073-1082.

DOI: https://doi.org/10.1046/j.1471-4159.2001.00490.x.

[88] Mandel S, Reznichenko L, Amit T, Youdim MB. Green tea polyphenol (-)-epigallocatechin-3gallate protects rat PC12 cells from apoptosis induced by serum withdrawal independent of P13Akt pathway. Neurotox Res. 2003; 5(6):419-24. DOI: https://doi.org/10.1007/BF03033171.

「891 Ittiyavirah SP, Ruby R. Effect of hydro-alcoholic root extract of Plumbago zeylanica 1 alone and its combination with aqueous leaf extract of Camellia sinensis on haloperidol induced parkinsonism in wistar rats. Ann Neurosci. 2014;21(2):47-50. DOI: https://doi.org/10.5214/ans.0972.7531.210204.

[90] Park KS, Eun JS, Kim HC, Moon DC, Hong JT, Oh KW. (-)-Epigallocatethin-3-O-gallate counteracts caffeine-induced hyperactivity: evidence of dopaminergic blockade. Behav Pharmacol. 2010; 21(5-6):572-575. DOI: https://doi.org/10.1097/fbp.0b013e32833beffb.

[91] Storch A, Jost WH, Vieregge P, Spiegel J, Greulich W, Durner J, Müller T, Kupsch A, Henningsen H, Oertel WH, Fuchs G, Kuhn W, Niklowitz P, Koch R, Herting B, Reichmann H. Randomized, doubleblind, placebocontrolled trial on symptomatic effects of coenzyme Q10 in parkinson disease. Arch. Neurol. 2007; 64 (7):938-944. DOI: https://doi.org/10.1001/archneur.64.7.nct60005.

[92] Cho HS, Kim S, Lee SY, Park JA, Kim SJ, Chun HS.Protective effect of the green tea component, L-theanine on environmental toxinsinduced neuronal cell death. Neurotoxicology. 2008; 29(4):656-662.

DOI: https://doi.org/10.1016/j.neuro.2008.03.004. 